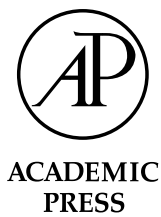

\title{
Grammatical feature selection in noun phrase production: Evidence from German and Dutch
}

\author{
Niels O. Schiller* and Alfonso Caramazza
}

Harvard University, Cambridge, MA, USA

Received 24 October 2001; revision received 4 April 2002

\begin{abstract}
In this study, we investigated grammatical feature selection during noun phrase production in German and Dutch. More specifically, we studied the conditions under which different grammatical genders select either the same or different determiners or suffixes. Pictures of one or two objects paired with a gender-congruent or a gender-incongruent distractor word were presented. Participants named the pictures using a singular or plural noun phrase with the appropriate determiner and/or adjective in German or Dutch. Significant effects of gender congruency were only obtained in the singular condition where the selection of determiners is governed by the target's gender, but not in the plural condition where the determiner is identical for all genders. When different suffixes were to be selected in the genderincongruent condition, no gender congruency effect was obtained. The results suggest that the so-called gender congruency effect is really a determiner congruency effect. The overall pattern of results is interpreted as indicating that grammatical feature selection is an automatic consequence of lexical node selection and therefore not subject to interference from other grammatical features. This implies that lexical node and grammatical feature selection operate with distinct principles.
\end{abstract}

(c) 2002 Elsevier Science (USA). All rights reserved.

Keywords: Speech production; Lexical access; Grammatical feature selection; Gender congruency

This study investigates how words are accessed and uttered in the course of speech production. To produce speech, different types of lexical information, including semantic, grammatical, and phonological specifications have to be retrieved from long-term memory. Most of the research in the area of lexical access has focused on the retrieval of the phonological form of nouns. However, for the production of noun phrases, for instance, access to

\footnotetext{
${ }^{*}$ Corresponding author. Present address: Department of Neurocognition, Faculty of Psychology, Universiteit Maastricht, P.O. Box 616, 6200 MD Maastricht, The Netherlands. Fax: +31-43-3884125; Max Planck Institute for Psycholinguistics, P.O. Box 310, 6500 AH Nijmegen, Netherlands. Fax: +3124-3521213.

E-mail addresses: n.schiller@psychology.unimaas.nl,niels. schiller@mpi.nl (N.O. Schiller).
}

grammatical or syntactic features of words, such as case, number, or gender, is also needed. In German, for instance, each noun has a specific gender. Furthermore, adjectives modifying a noun require a gender-marked suffix that agrees with the gender of the noun. Take the German sentence " $\operatorname{Ein}_{(\mathrm{nom}, \mathrm{sg})}$ grünes $_{(\mathrm{nom}, \mathrm{sg})}$ Fenster $_{(\mathrm{nom}, \mathrm{sg})}$ $\operatorname{des}_{(\mathrm{gen}, \mathrm{sg})}$ roten $_{(\mathrm{gen}, \mathrm{sg})}$ Hauses $_{(\mathrm{gen}, \mathrm{sg})}$ ist $_{(\mathrm{sg})}$ schmutzig" [A green window of the red house is dirty] as an example. ${ }^{1}$ The word Hauses is the genitive singular form of the neuter noun Haus ('house'). Since the determiner (e.g., das 'the'; genitive form: des 'of the') and the adjective (e.g., rot 'red') are syntactically dependent on the noun and thus

\footnotetext{
${ }^{1}$ We use the following abbreviations: nom for nominative, gen for genitive, sg for singular, $\mathrm{pl}$ for plural, com for common gender, neu for neuter gender, mas for masculine gender, and fem for feminine gender.
} 
have to agree with it in case, number, and gender, the syntactic features of the noun have to be retrieved.

The gender of a noun is an essentially arbitrary lexical property (Corbett, 1991). This becomes apparent when we consider the different genders of nouns referring to the same entity across languages. For example, the word for car is neuter in German (das Auto), feminine in French (la voiture), masculine in Spanish (el coche), and it has common gender in Dutch (de auto). This suggests that the gender of a noun is a grammatical property of the lexical system of a given language (see also Caramazza \& Miozzo, 1997; Levelt, 1989; Schriefers, 1993). Thus, the study of gender feature retrieval provides a window into the mechanisms that govern the selection of lexical grammatical features and their role in determiner and inflectional morphology processing. In this study, we investigate the selection of a word's gender in the course of noun phrase (NP) production.

\section{Syntactic processes in speech production involving gender}

Schriefers (1993) used the picture-word interference paradigm to investigate the syntactic processes involved in selecting the definite article and the adjective's inflection in NP production by Dutch speakers. He presented his participants with colored line drawings and asked them to name the objects by producing a determiner(Det)-adjective(Adj) NP (e.g., het groene boek $_{\text {neu }}$ 'the green book' vs. de groene tafel $\mathrm{c}_{\text {com }}$ 'the green table,' Exp. 1) or a plain adjective NP (e.g., groen boek 'green book' vs. groene tafel $l_{\text {com }}$ 'green table,' Exp. 2). Distractor words were presented at different stimulus onset asynchronies (SOAs) relative to the onset of picture presentation. The words were either of the same or different gender as the picture name. On the assumption that noun lexical nodes automatically activate their gender information, gender incongruence between target picture and distractor word could delay the selection of the correct gender information if one assumed that selection of gender nodes is a competitive process.

Schriefers (1993) obtained faster reaction times at SOA $0 \mathrm{~ms}$ in both experiments when target picture and distractor word had the same gender than when they had different genders. At SOA $-200 \mathrm{~ms}$ (i.e., the distractor is presented $200 \mathrm{~ms}$ before picture onset) the effect of gender congruency was only significant in the first experiment, and at SOA $+450 \mathrm{~ms}$ (i.e., the distractor is presented $450 \mathrm{~ms}$ after picture onset) there was no effect at all. Van Berkum (1997) and La Heij, Mak, Sander, and Willeboordse (1998) replicated the gender congruency effect in Dutch and Schriefers and Teruel (2000) obtained similar effects in German. Schriefers (1993) interpreted this gender congruency effect as reflecting competition in the selection of a word's syntactic features, which we will label the gender selection interfer- ence hypothesis (GSIH). He argued that the activation of the gender feature of the distractor word interferes with the naming of the picture in those cases where the distractor's gender is different from that of the target noun. This is because two different gender specifications compete for selection in the gender-incongruent condition, whereas only one gender is activated in the gendercongruent condition. The gender congruency effect was absent, however, when nouns were named without determiners (La Heij et al., 1998). Levelt, Roelofs, and Meyer (1999) interpreted this result as follows: When no determiner is needed in speech production, no gender feature is selected (although the gender features of target and distractor become automatically activated). Therefore, there is no gender feature competition in the bare noun naming condition, and hence a gender congruency effect does not occur in such a situation.

However, Miozzo and Caramazza (1999) did not find a gender congruency effect in Italian and Costa, Sebastián-Gallés, Miozzo, and Caramazza (1999) failed to replicate the effect in Catalan and in Spanish (see also Miozzo, Costa, and Caramazza, 2002). Similarly, Alario and Caramazza (2002) failed to find a gender congruency effect in French. Miozzo and Caramazza (1999) proposed two possibilities for why they failed to replicate Schriefers' (1993) results in Italian. One possibility is that gender selection interference occurs in all gendermarking languages but that specific properties of individual languages may be responsible that the effect does not surface. The other possibility is that the putative gender congruency effect observed in Dutch is really a determiner selection interference effect that is only found in languages where determiner selection can occur very early in the NP production process - the determiner selection interference hypothesis (DSIH).

Miozzo and Caramazza (1999) noted that there is an important difference between the determiner systems in Dutch and in Italian. In Dutch, the determiner form in an NP can be selected on the basis of the noun's gender alone. The determiner for common gender singular nouns is de and for neuter gender singular nouns it is het in all contexts. Once the noun's gender has been selected, its associated determiner form can be immediately selected for production. In Romance languages like Italian, Catalan, Spanish, or French, the selection of the appropriate determiner form is not fully determined by a noun's gender, but also depends on the local phonological context in which the determiner occurs - the onset of either the noun in Det $+\mathrm{N}$ or Det $+\mathrm{N}+\mathrm{Adj}$ phrases or the adjective in Det $+\mathrm{Adj}+\mathrm{N}$ phrases. In Italian, for example, the singular masculine definite article can be either il or lo depending on the phonology of the word that follows it. This can be clearly appreciated when we consider the following contrasts: il tavolo ('the table') but lo strano tavolo ('the strange table'), and lo scienziato ('the scientist') but il grande scienziato ('the 
great scientist'). In these examples it is clear that the form of the determiner does not depend only on the gender of the noun (masculine), or only on the gender of the noun and its phonology, but on the gender of the noun plus local phonological context-select lo if the immediately following phonological context is a vowel, a consonant cluster of the type $\langle\mathrm{s}\rangle+$ consonant or $\langle\mathrm{gn}\rangle$, or an affricate, otherwise select il. This means that the selection of the determiner in an NP must wait until the immediately following phonological context has been specified - a fairly late process in NP production. Thus, a major difference between Italian and Dutch is the point at which enough information is available for the selection of a determiner form. In Dutch, this point is immediately after the selection of the noun's gender feature; in Italian, this point occurs much later, at the level where the segmental content of nouns and adjectives is specified.

This difference in the structure of the determiner systems in Dutch and in Italian (and other Romance languages) could have one of two possible implications. One possibility is that even if gender selection were a competitive process in Italian (as has been argued for Dutch), its effects would not be visible because determiner form selection occurs very late in this language and therefore any selection conflict at the level where gender information is specified would be resolved by the time determiner form selection takes place. The other possible implication is that even if gender selection were a non-competitive process in Dutch (and other languages) there could still be effects of "gender congruency" in Dutch but not in Italian. However, the locus of the effect would now be at the level of determiner selection and not gender feature selection. That is, if we assumed that determiner form selection is a competitive process, we might expect slower determiner selection when target and distractor nouns have different genders. This is because in Dutch the selection of the appropriate determiner can be made as soon as the gender information of a noun becomes available and, therefore, the activation of a competing determiner (through the activation of the gender of the distractor noun) would interfere with the selection of the target determiner. In Italian, however, determiner form selection occurs so late in the process of NP production that the activation of competing gender information and its associated determiners would long have dissipated, rendering ineffective any competing activation.

In this study, we investigate whether the gender congruency effect occurs at the level of gender selection proper or rather later, i.e., at the level of determiner selection. This is important for language production research because it may tell us whether the selection of abstract features, such as gender, is a competitive process during speech production or whether competition only occurs if different phonological forms, e.g., deter- miners, are activated. We test this in German and Dutch, languages in which the choice of determiners does not depend on phonological context. Therefore, selection of the determiner can be made immediately after selection of a noun's grammatical features (gender, number, and case). Thus our expectation is that we should replicate the "gender congruency effect" in similar conditions to those reported in earlier studies. However, German and Dutch have the interesting property that determiners are gender marked only in the singular and not in the plural. Thus, in German, different determiners are selected for masculine, feminine, and neuter nouns when used in the singular (in the nominative case the determiners are, respectively, der, die, and das) but the same determiner is used for all genders in the plural (in the nominative case it is the determiner die).

As already noted, German distinguishes three genders in the noun system, i.e., feminine (fem), masculine (mas), and neuter (neu). ${ }^{2}$ However, gender is not explicitly marked on the noun but realized via an appropriate determiner, e.g., die Wand ('the wall' fem), der Tisch ('the table,' mas), das Buch ('the book,' neu). ${ }^{3}$ In the plural, the determiner for all three genders is die, e.g., die Wände ('the walls,' fem), die Tische ('the tables,' mas), die Bücher ('the books,' neu). The Dutch determiner system is similar to the German one in that different determiners are associated with different genders in the singular, but not in the plural. In the singular, the

\footnotetext{
${ }^{2}$ The distribution of the three genders in German is as follows. There are 4164 monomorphemic nouns listed in the CELEX database (Baayen, Piepenbrock, \& Gulikers, 1995). Fifty-one of these have multiple genders (e.g., der See ['the lake'] vs. die See ['the sea']). Of the remaining 4113 entries, 1758 $(42.74 \%)$ have masculine gender, $1567(38.10 \%)$ have feminine gender, and $788(19.16 \%)$ are neuter. If one takes word frequency into account (each entry multiplied by its frequency of occurrence), the following picture emerges: masculine$38.76 \%$, feminine- $35.36 \%$, and neuter $-25.88 \%$.

${ }^{3}$ Most German nouns have fixed gender. However, there is a minority of words that can take more than one gender. Most of them are homophones, e.g., der See ('the lake,' mas) vs. die See ('the sea,' fem), some are words with varying gender, e.g., der or das Filter ('the filter,' mas or neu). Historically, gender was probably a "real" grammatical category_-just like number, for instance - that allowed speakers to choose between different values. For instance, Lehmann (1958) reconstructed the following forms for Indo-European: hímah ('winter,' fem), himás ('cold,' mas), and himam ('snow,' neu). That is, gender was used to express certain perspectives with respect to a lexical item. Leiss (1999) showed that even in Old High German nouns with different genders still existed, such as bluomo ('flower,' mas) and bluoma ('blossom,' fem). That is, different suffixes used to realize gender-specific categorical meanings on the nouns. However, this full-fledged gender system collapsed and is no longer functioning in New High German.
} 
determiner de is used for common gender (com) and het for neuter gender (neu), as for instance in de tafel ('the table,' com) or het boek ('the book,' neu). ${ }^{4}$ In the plural, Dutch is like German in that it uses only one determiner for both genders, namely de, as in de tafels ('the tables,' com) or de boeken ('the books,' neu).

The fact that in specific conditions a single determiner form is used for different genders in the German and the Dutch determiner systems affords the opportunity to distinguish between the two hypothesized causes of the gender congruency effect - the gender (GSIH) and the determiner selection interference hypotheses (DSIH). If the gender congruency effect is caused by interference at the level of gender feature selection, we should observe the effect in the production of both singular and plural NPs. This is because according to the GSIH the interference effect is independent of determiner form properties. However, if the gender congruency effect is caused by interference at the level of determiner selection (DSIH), we should not observe such an effect when the same determiner form is required by the target and the distractor word, independently of whether or not the two nouns have the same gender. These conditions are met in some cases of plural NP production and form the basis for the research reported here.

Consider the following German example. Suppose that a subject is presented with a picture of a cup $\left(\right.$ Pokal $\left._{\text {mas,sg }}\right)$ and the distractor words Schlange fem, $\mathrm{sg}$

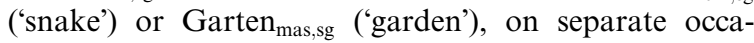
sions. The required response in both cases is der Pokal ('the cup'). According to the GSIH, which assumes that the selection of grammatical features is a competitive process, naming latencies should be slower when the distractor word is Schlange $_{\text {fem,sg }}$ than when it is

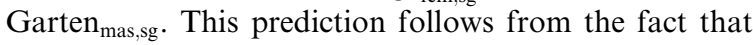
the gender features in the picture-word pair Pokal/ Schlange are not congruent (masculine and feminine, respectively) but they are congruent in the pair Pokal/ Garten (both masculine). The DSIH, which assumes that determiner but not grammatical feature selection is a competitive process, also predicts a gender congruency effect in this case. But the basis for the effect is different. On this hypothesis, it results from the fact that different determiners are associated with Pokal and Schlange (der and die, respectively), whereas the same determiner (der) is associated with Pokal and Garten, and therefore the

\footnotetext{
${ }^{4}$ The distribution of the two genders in Dutch is as follows (see Van Berkum, 1996): There are 6349 monomorphemic nouns list in CELEX, 77 (1.2\%) of which are unclassifiable. Of the remaining 6272 entries $4982(78.5 \%)$ have common gender and $1290(20.3 \%)$ have neuter gender. If word frequency is taken into account, the situation changes a bit. Now $70.3 \%$ of the monomorphemic nouns have common gender and 29.6\% have neuter gender (counts taken from Van Berkum, 1996).
}

former but not the latter pairing would result in determiner selection interference.

Consider now the slightly different situation where a subject is presented with a picture of two cups (Pokale $_{\text {mas,pl }}$ ) and the distractor words Schlangen $_{\text {fem,pl }}$ ('snakes') or Gärten mas,pl ('gardens'). Now, the required response is die Pokale ('the cups'). According to the GSIH, a gender congruency effect is also expected here, for the same reason described in the case of singular NP production. This is because changing the number of the NP has not altered the gender feature relation between target and distractor word and therefore we expect interference for the picture-word pair Pokale/Schlangen relative to the pair Pokale/Gärten. By contrast, the DSIH predicts that there should not be a gender congruency effect in the case of plural NP production. This is because in the latter case the determiners associated with the target and distractor words do not vary as a function of their gender (the determiner is die in all cases), and therefore there is no basis for determiner selection interference. Thus, although the GSIH and the DSIH make identical predictions for the effects of gender congruency in the production of singular NPs, albeit for different reasons, they make different predictions for plural NP production. The investigation of singular and plural NP production in German (and Dutch) provides the opportunity to distinguish between the two hypotheses.

However, the precise conditions that would allow a comparison of the GSIH and the DSIH depend on certain assumptions about the way in which distractor words affect the production of the target NP. Implicit in the predictions we have derived for the production of singular and plural NPs from the two hypotheses under consideration here is the assumption that the processing of a distractor word influences the production system in certain ways. Specifically, it is assumed that the distractor word activates its corresponding lexical node and associated grammatical features in the production network. The general plausibility of this assumption has been confirmed by the studies showing a gender congruency effect in NP production (Costa, Kovacic, \& Caramazza, submitted; La Heij et al., 1998; Schriefers, 1993; Schriefers \& Teruel, 2000; Van Berkum, 1997). That is, the gender congruency effect can be taken to indicate that the gender feature of the distractor word is activated in the picture-word interference task when NPs are produced. However, it is far from obvious whether this assumption applies also to the number feature of a noun. This is because while gender is an intrinsic feature of nouns, number is a diacritic value that is fixed by semantic context. Therefore, it is possible that the activation and selection of these two types of features may be subject to different principles (Caramazza, 1997; Levelt et al., 1999). 
Consider the production of the NPs der Pokal mas,sg $_{\text {s }}$

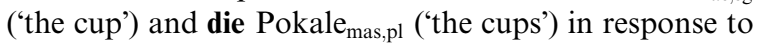
pictures of one cup and two cups, respectively. The selection of der and die is determined jointly by an intrinsic feature of the noun-the gender feature masculine - and by a contextual property-the number diacritic singular or plural. Setting a specific value for the feature number depends on factors external to the noun in the NP. ${ }^{5}$ The diacritics singular and plural depend only on the number of objects in the picture and not the objects themselves. This difference between gender and number features is reflected in the way in which they are selected for inclusion in the determiner frame. That is, whereas selection of the feature gender depends entirely on the selection of a specific noun node in the lexical system, the selection of the number diacritic depends on phrasal and not lexical features. In the context of the picture-word interference task this difference translates into highly discrepant roles for lexical and extra-lexical information in selecting, respectively, the gender and number features for the determiner, and this could have implications for the role of the distractor word's number in this task.

Consider now the case in which a picture showing two cups (die Pokale mas,pl $_{\text {) }}$ ) is paired with the distractor word

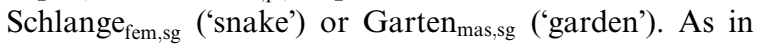
previous cases, the GSIH predicts slower naming latencies for the pairing Pokale mas,pl $_{\text {s }} /$ Schlange $_{\mathrm{fem}, \mathrm{sg}}$ than the pairing Pokale mas,pl $/$ Garten $_{\text {mas,sg }}$, since in the former but not the latter case there is a mismatch of gender features. (A generalization of this hypothesis to all grammatical features might also predict a number congruency effect if selection of the value of number diacritics obeyed the same principles as the selection of gender features. However, we have pursued this issue elsewhere; see Schiller \& Caramazza, 2002.) The predictions made by the DSIH are not straightforward, and depend on the way in which the number information of the distractor word is processed. If the number feature of the distractor word is considered for possible selection into the determiner frame for production, then, we would expect the pairing Pokale $_{\text {mas,pl }} /$ Garten $_{\text {mas,sg }}$ to be produced more slowly than the pairing Pokale $_{\text {mas,pl }} /$ Schlange $_{\text {fem }, \mathrm{sg}}$ - the reverse of what is predicted by the GSIH. This is because different determiners are associated with Pokale $e_{\text {mas,pl }}$ and

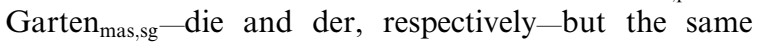
determiner, die, for Pokale $_{\text {mas,pl }}$ and Schlange $\mathrm{fem}_{\mathrm{fg}}$. However, if the number of the distractor is not considered for insertion into the determiner frame, then the DSIH predicts no difference between the two pairings; that is, no effect of gender (or number) congruency. Once again, this prediction rests on the assumption that the

\footnotetext{
${ }^{5}$ For the sake of simplicity we omit discussion of the possible role of the noun feature mass/count.
}

number feature for the determiner frames for the target noun and the distractor word are both determined extralexically; that is, by the number of objects in the picture and not the morphology of the distractor word. Support for this assumption comes from two experiments by Schiller and Caramazza (2002) in which the selection of the number feature was investigated in German with the picture-word interference task. In these experiments, no effect of number activation of the distractor words could be found, suggesting (a) that the selection of the number feature is not a competitive process and (b) that the number feature is set extra-lexically. The most likely candidate for setting the determiner frame for the number feature of the distractor word is the picture itself since it contextually defines the number feature that has to be selected for production.

In short, the predictions that can be derived for the DSIH in the picture-word interference task do not depend only on the gender of the target and distractor nouns but also on other properties of the NP production tasks. Nonetheless, the GSIH and DSIH make distinct predictions for the production of singular and plural NPs. The GSIH predicts a gender congruency effect independently of whether production involves singular or plural NPs. The DSIH makes more complex predictions, but one thing is clear: Different patterns of results are expected for singular and plural NPs. Therefore, we can use the picture-word interference task with singular and plural NPs to distinguish between the two hypotheses.

There is one further issue that can be tested using the gender congruency effect. The DSIH suggests that the determiner forms of the corresponding target and distractor nouns cause the gender congruency effect. According to the discrete serial stage model by Levelt et al. (1999) such an account would not be possible because only selected lexical nodes can activate their word forms. However, since the distractor word is never produced and therefore its lexical node has never been selected, how could its corresponding determiner form be activated and compete for selection with the determiner form of the target noun? In order for this to happen, some cascaded processing of information must be allowed. Therefore, the test between the GSIH and the DSIH may also serve to test a more general aspect of speech production theories, namely the issue of serial vs. cascaded processing.

The method we use to contrast the GSIH and the DSIH is the picture-word interference paradigm. In this paradigm, participants are instructed to name a picture while ignoring a simultaneously presented distractor word. This task is a variant of the Stroop (1935) paradigm and it has been used successfully to investigate various aspects of lexical access in language production (for reviews see Glaser, 1992; MacLeod, 1991). Several researchers have shown that picture naming latencies are affected by specific properties of the to-be-ignored word 
(e.g., Glaser \& Düngelhoff, 1984; Glaser \& Glaser, 1989; Lupker, 1979, 1982; Meyer, 1996; Meyer \& Schriefers, 1991; Posnansky \& Rayner, 1977; Rosinski, Golinkoff, \& Kukish, 1975; Schriefers, 1992; Schriefers, Meyer, \& Levelt, 1990). The properties that have been investigated most thoroughly are the semantic and phonological relationship between the name of the picture and the distractor word. More recently, the relationship between the gender of the picture's name and that of the distractor word has been the focus of intense investigation because of its potential value in revealing how the grammatical features of words are activated and selected (e.g., Costa et al., 1999; La Heij et al., 1998; Miozzo \& Caramazza, 1999; Schriefers, 1993; Van Berkum, 1997). Here, we use this paradigm to investigate the process of gender selection in NP production.

\section{Experiments 1a, 1b, and 1c: Noun phrase production in German}

In our first three experiments, we attempted to replicate and to extend the gender congruency effect in German to determine at which level of NP production the effect occurs, i.e., gender selection or determiner selection. Native German participants were required to name a set of pictures. Each picture was paired with a gender-congruent distractor word and with a genderincongruent distractor word. Pictures could either appear as single objects (singular condition) or as two identical objects (plural condition). Participants were asked to name the picture with the appropriate determiner (Exp. 1a), e.g., der Tisch ('the table') or die Tische ('the tables'), or with the appropriate adjective (Exp. 1b), e.g., roter Tisch ('red table') or rote Tische ('red tables'), or with the appropriate determiner + adjective (Exp. 1c), e.g., der rote Tisch ('the red table') or die roten Tische ('the red tables'). The Det $+\mathrm{N}$ naming task is equivalent to the task employed by Costa et al. (1999), La Heij et al. (1998), Miozzo and Caramazza (1999), and Schriefers and Teruel (2000). The Adj $+\mathrm{N}$ task is similar to the task employed by Schriefers (1993) and the Det $+\mathrm{Adj}+\mathrm{N}$ task is equivalent to the task employed by Schriefers (1993) and Schriefers and Teruel (2000). The gender selection and determiner selection interference hypotheses make different predictions in naming singular and plural NPs. The GSIH predicts a gender congruency effect independently of whether production involves singular or plural NPs. The DSIH predicts different effects for singular and plural NPs although the precise pattern of interference effects depends on other assumptions about the role of distractor number in determiner selection. Because the precise role of these other factors remains unclear, we will not attempt to spell out all the possible patterns. Instead we will allow the results to help us further define the factors that contribute to number feature selection and their role in the picture-word naming task.

\section{Method}

\section{Participants}

Experiment 1a had 27 participants, Experiment 1b had 25 participants, and Experiment 1c had 26 participants. All participants were native German students from the Catholic University of Eichstätt in Germany. They were paid for their participation or received course credits. None of them participated in more than one experiment.

\section{Materials}

Sixty target pictures corresponding to monomorphemic German nouns were selected for naming. There were equally many feminine, masculine, and neuter picture names (e.g., die Tür 'the door,' fem; der Tisch 'the table,' mas; das Buch 'the book,' neu). Picture names were selected such that formal correspondences between phonological properties and grammatical gender were avoided (Köpcke \& Zubin, 1984). The mean frequency of occurrence per one million word forms was similar for the feminine, the masculine, and the neuter picture names. Each picture was paired with a gender-congruent and a gender-incongruent distractor word. There were equally many incongruent distractor words from the two incongruent genders (e.g., half of the 20 feminine targets were paired with masculine distractor words and the other half with neuter distractor words, etc.). The distractor words had similar frequency characteristics as the picture names. Mean length in syllables and segments was matched between the congruent and incongruent distractor words. Distractor words were semantically and phonologically unrelated to the picture names. In addition to the 60 target pictures, there were ten practice pictures paired with distractors according to the same criteria as the target pictures. The complete list of target pictures and distractor words can be found in Appendix A. Pictures were simple black (Exp. 1a) or colored (Exp.'s 1b and 1c) line drawings of everyday objects presented on a white background. They were taken from the pool of pictures of the Max Planck Institute for Psycholinguistics in Nijmegen. Distractor words were displayed in their singular form in black characters (font type and size: Geneva, 30 pts.) in, across, or between the object(s). Pictures appeared in the center of the screen with the distractor words appearing at slightly different positions around fixation to prevent participants from ignoring the distractors. For an individual picture, however, the position of the two distractor words was the same.

\section{Procedure}

Participants were tested individually in a dimly lit testing room. They sat in front of a computer screen 
at a viewing distance of approximately $80 \mathrm{~cm}$. The experimenter sat in the same room to score potential errors. The computer screen was a Macintosh Color Display. On each trial, a fixation point appeared for $500 \mathrm{~ms}$ followed by the picture and the distractor word. Distractor words were always presented without their determiners. Participants were instructed to fixate the fixation point and to name the target picture as quickly and as accurately as possible with the appropriate determiner (Exp. 1a), or with the appropriate adjective (Exp. 1b), or with the appropriate determiner + adjective (Exp. 1c) in German. At picture onset, a voice key connected to a microphone was activated to measure the naming latencies. As soon as a response was given and the voice key was triggered, picture and distractor word disappeared from the screen and after a short pause of one second the next trial started. If no response was recorded within two seconds, the next trial started automatically. The presentation of the trial sequences was controlled by PsychLab version1.0-103.1 (Gum \& Bub, 1988). A response was considered invalid when it exceeded the response deadline of two seconds, when it included a speech error, when a wrong determiner or picture name was produced, or when the voice key was triggered incorrectly. Invalid responses were excluded from the reaction time analyses.

\section{Design}

The experiment consisted of three parts. First, participants were engaged in a familiarization phase. They saw each picture once on the computer screen to become familiarized with the pictures and learn the designated picture names (in case alternative names were preferred by the participants). Each picture appeared on the screen as a black-on-white line drawing and after two seconds the designated name was added below the picture. Both remained in view for another three seconds. Participants were asked to use the designated name for each picture. After the familiarization phase, participants received a practice phase during which each picture was presented once as single objects (singular condition) and once as two objects (plural condition) in the center of the screen preceded by a fixation point. Pictures were presented in black (Exp. 1a) or once in red and once in green (Exp.'s $1 b$ and 1c). Participants' task was to name the picture as quickly and as accurately as possible using the appropriate determiner and picture name (Exp. 1a), e.g., der Tisch ('the table') or die Tische ('the tables') or adding the appropriate determiner and adjective (Exp.'s $1 \mathrm{~b}$ and 1c), e.g., der rote Tisch ('the red table') or die roten Tische ('the red tables'). This procedure was adopted to make sure that participants knew the correct determiner for each picture name. After completion of the practice phase, the experimenter cor- rected participants in case they did not use the designated name for a given picture. ${ }^{6}$

The naming phase began immediately after the practice phase. Stimuli were presented in four blocks of 70 trials each. In Experiments $1 \mathrm{~b}$ and 1c, half of the pictures of each gender were presented in green in the singular condition and in red in the plural condition, the other half in red in the singular condition and in green in the plural condition. The SOA was $0 \mathrm{~ms}$. The first 10 trials of each block were taken from the set of practice pictures and served as warm-up trials. They were not included in the analyses. In each block, targets and distractors of the three grammatical genders were represented approximately equally. Blocks were randomized individually for each participant with the following constraints: (a) before the same object was presented again, at least four other objects appeared in between; (b) targets could have the same number on no more than two consecutive trials; and (c) targets could have the same gender on no more than two consecutive trials; and (d) (only in Exp.'s 1b and 1c) targets could have the same color on no more than two consecutive trials. Finally, the order of the blocks was varied across participants. Each experiment lasted approximately one hour.

\section{Results}

Naming latencies shorter than $350 \mathrm{~ms}$ and longer than $1500 \mathrm{~ms}$ were counted as outliers (Exp. 1a: $1.5 \%$ of the data; Exp. 1b: $1.5 \%$ of the data; Exp. 1c: $4.1 \%$ of the data). The mean naming latencies and error rates are summarized in Tables 1-3. Analyses of variance were run with Number of Target (singular or plural) and Gender Condition (congruent or incongruent) as independent variables. Separate analyses were carried out with participants $\left(F_{1}\right)$ and items $\left(F_{2}\right)$ as random variables.

\footnotetext{
${ }^{6}$ The practice phase of Experiment 1a was very similar to the Experiments 1 and 3 by Schriefers, Jescheniak, and Hantsch (2002), namely Det-NP naming in German without distractor words. Furthermore, Schriefers et al. (2002) used the same materials as we did in Experiment 1a. Schriefers et al. (2002) found a cost for masculine and neuter plural NPs relative to their singular NPs while for feminine NPs no such cost was observed. Analyses of the practice blocks in Experiment 1a yielded the following results: For both masculine and neuter plural NPs there was a cost of $77 \mathrm{~ms}$ compared to their respective singular NPs (mas, sg: $695 \mathrm{~ms}$; mas, pl: $772 \mathrm{~ms}$; neu, sg: $703 \mathrm{~ms}$; neu, pl: $780 \mathrm{~ms}$ ) whereas feminine plural NPs did not show such a cost (fem, sg: $753 \mathrm{~ms}$; fem, pl: $757 \mathrm{~ms}$ ). The interaction between Gender and Number is significant by participants $\left(F_{1}(2,50)=15.92, M S_{\mathrm{e}}=1332.44, p<.01\right)$ but not by items $\left(F_{2}(2,57)<1\right)$. These data once more support the view that gender is accessed in German plural NPs and that for the production of plural Det NPs, singular and plural determiners compete for selection.
} 
Table 1

Mean naming latencies (in ms) and percentage errors (in parentheses) in Experiment 1a (German Det + Noun naming)

\begin{tabular}{|c|c|c|c|c|c|}
\hline \multirow{2}{*}{$\begin{array}{l}\text { Number of } \\
\text { Target }\end{array}$} & \multirow[t]{2}{*}{ Gender Condition } & \multicolumn{3}{|c|}{ Gender of Target } & \multirow[t]{2}{*}{ Mean } \\
\hline & & Feminine & Masculine & Neuter & \\
\hline \multicolumn{6}{|l|}{ Singular } \\
\hline & Congruent & $774(3.7)$ & $739(3.5)$ & $736(3.1)$ & $750(3.5)$ \\
\hline & Incongruent & $790(3.0)$ & $753(3.3)$ & $768(3.5)$ & $770(3.3)$ \\
\hline \multicolumn{6}{|l|}{ Plural } \\
\hline & Congruent & $750(3.3)$ & $773(3.7)$ & $778(2.6)$ & $767(3.2)$ \\
\hline & Incongruent & $740(1.5)$ & $763(5.4)$ & $772(4.6)$ & $758(3.8)$ \\
\hline
\end{tabular}

Table 2

Mean naming latencies (in ms) and percentage errors (in parentheses) in Experiment $1 \mathrm{~b}$ (German Adj + Noun naming)

\begin{tabular}{llllll}
\hline \multirow{2}{*}{$\begin{array}{l}\text { Number of } \\
\text { Target }\end{array}$} & Gender Condition & \multicolumn{3}{c}{ Mean } \\
\cline { 3 - 5 } & & Feminine & Masculine & Neuter \\
\hline Singular & & & & & \\
& Congruent & $785(6.2)$ & $790(5.2)$ & $794(4.8)$ & $790(5.4)$ \\
& Incongruent & $785(5.8)$ & $785(6.4)$ & $791(5.4)$ & $787(6.1)$ \\
Plural & & & & $776(6.6)$ & $779(6.7)$ \\
& Congruent & $779(7.2)$ & $781(6.4)$ & $776(4.2)$ & $773(5.2)$ \\
\hline
\end{tabular}

Table 3

Mean naming latencies (in ms) and percentage errors (in parentheses) in Experiment 1c (German Det + Adj + Noun naming)

\begin{tabular}{|c|c|c|c|c|c|}
\hline \multirow{2}{*}{$\begin{array}{l}\text { Number of } \\
\text { Target }\end{array}$} & \multirow[t]{2}{*}{ Gender Condition } & \multicolumn{3}{|c|}{ Gender of Target } & \multirow[t]{2}{*}{ Mean } \\
\hline & & Feminine & Masculine & Neuter & \\
\hline \multicolumn{6}{|l|}{ Singular } \\
\hline & Congruent & $752(7.7)$ & 735 (12.1) & $766(6.7)$ & $751(8.8)$ \\
\hline & Incongruent & $764(11.5)$ & $753(11.0)$ & $784(10.6)$ & $767(11.0)$ \\
\hline \multicolumn{6}{|l|}{ Plural } \\
\hline & Congruent & $718(5.6)$ & $726(5.4)$ & $712(7.1)$ & $719(6.7)$ \\
\hline & Incongruent & $706(5.8)$ & $715(7.3)$ & $714(7.5)$ & $712(6.9)$ \\
\hline
\end{tabular}

\section{Experiment 1 a}

Overall, there was a $6 \mathrm{~ms}$ advantage in the gendercongruent condition $(758 \mathrm{~ms})$ over the gender-incongruent condition (764 ms). This effect of Gender Condition was significant by participants $\left(F_{1}(1,26)=5.59\right.$, $\left.M S_{\mathrm{e}}=172.46, p<.05\right)$ but not by items $\left(F_{2}(1,59)=2.14\right.$, $M S_{\mathrm{e}}=1096.09$, n.s.). Pictures were named slightly faster in the singular $(760 \mathrm{~ms})$ than in the plural $(763 \mathrm{~ms})$, but this difference was not significant (both $F \mathrm{~s}<1$ ). However, the effect of gender match was modulated by the number of the target indicated by a significant interaction between Number of Target and Gender Condition $\left(F_{1}(1,26)=\right.$ $18.06, M S_{\mathrm{e}}=302.15, p<.01 ; F_{2}(1,59)=18.51, M S_{\mathrm{e}}=$ $677.76, p<.01)$. In the singular, there was a $20 \mathrm{~ms}$ gender congruency effect (gender-congruent: $750 \mathrm{~ms}$, gender-incongruent: $770 \mathrm{~ms}$ ), whereas in the plural, there was a $9 \mathrm{~ms}$ advantage of the gender-incongruent condition (758 ms) over the gender-congruent condition $(767 \mathrm{~ms})$. Analyses of the simple effects revealed that the congruency effect in the singular was reliable $\left(F_{1}(1,26)=17.07, M S_{\mathrm{e}}=322.56\right.$, $\left.p<.01 ; F_{2}(1,59)=10.92, M S_{\mathrm{e}}=1178.11, p<.01\right)$. The greater interference for gender-congruent target-distractor pairs in the plural was significant by subjects $\left(F_{1}(1,26)\right.$ $\left.=6.03, M S_{\mathrm{e}}=152.04, \quad p<.05\right)$ but not by items $\left(F_{2}(1,59)=3.40 ; M S_{\mathrm{e}}=595.74 ;\right.$ n.s. $)$. There were no significant effects in the error data.

\section{Experiment $1 b$}

Pictures were named faster in the plural condition $(776 \mathrm{~ms})$ than in the singular condition $(788 \mathrm{~ms})$. This $12 \mathrm{~ms}$ advantage was statistically significant $F_{1}(1,24)=12.51, M S_{\mathrm{e}}=382.91, \quad p<.01 ; \quad F_{2}(1,59)=$ 
5.69, $M S_{\mathrm{e}}=1792.11, p<.05 .^{7}$ However, the effect of Number of Target could be due to a speed/accuracy trade off, since the error analyses revealed that participants made more errors in the plural condition than in the singular condition (both $p$ 's $<.01$ ). No other effects in the error rates were found to be significant. Picture naming latencies were $4 \mathrm{~ms}$ faster in the gender-incongruent condition $(780 \mathrm{~ms})$ than in the gender-congruent condition (784 ms). The effect of Gender Condition was not significant $\left(F_{1}(1,24)=1.10, M S_{\mathrm{e}}=468.32\right.$, n.s.; $F_{2}(1,59)=$ $1.17, M S_{\mathrm{e}}=1124.10$, n.s.) nor was the interaction between Gender Condition and Number of Target $\left(F_{1}(1,24)=\right.$ $1.01, M S_{\mathrm{e}}=184.39$, n.s.; $\left.F_{2}(1,59)<1\right)$.

\section{Experiment 1c}

Pictures were named faster in the plural condition $(715 \mathrm{~ms})$ than in the singular condition $(759 \mathrm{~ms})$. This $44 \mathrm{~ms}$ advantage was statistically significant $\left(F_{1}(1,25)=\right.$ $79.68, M S_{\mathrm{e}}=49608.25, p<.01 ; F_{2}(1,59)=33.99, M S_{\mathrm{e}}=$ $128172.68, p<.01)$. Picture naming latencies were $4 \mathrm{~ms}$ faster in the gender-congruent condition $(735 \mathrm{~ms})$ than in the gender-incongruent condition $(739 \mathrm{~ms})$. The effect of Gender Condition was not significant $\left(F_{1}(1,25)=1.59\right.$, $M S_{\mathrm{e}}=362.93$, n.s.; $\left.F_{2}(1,59)<1\right)$, but the interaction between Gender Condition and Number of Target was highly significant $\left(F_{1}(1,25)=15.83, \quad M S_{\mathrm{e}}=3587.04\right.$, $\left.p<.01 ; F_{2}(1,59)=10.52, M S_{\mathrm{e}}=7482.34, p<.01\right)$. This interaction reflects the fact that singular targets were named $16 \mathrm{~ms}$ slower in the gender-incongruent condition $(767 \mathrm{~ms})$ than in the gender-congruent condition $(751 \mathrm{~ms})$, whereas plural targets were named slightly faster in the gender-incongruent condition $(712 \mathrm{~ms})$ than in the gender-congruent condition $(719 \mathrm{~ms})$. Analyses of simple effects showed that the effect of Gender Condition was significant in the singular $\left(F_{1}(1,25)=21.31, M S_{\mathrm{e}}=\right.$ $3115.97, p<.01 ; F_{2}(1,59)=4.87, M S_{\mathrm{e}}=5879.44, p<$ $.05)$ but not in the plural $\left(F_{1}(1,25)=2.70, M S_{\mathrm{e}}=834.00\right.$, n.s.; $F_{2}(1,59)=3.85, M S_{\mathrm{e}}=2084.17$, n.s. $)$.

The RT results were partially supported by the error data. Pictures in the singular $(9.9 \%)$ produced more errors than pictures in the plural $(6.8 \%)$. This effect was significant $\left(F_{1}(1,25)=11.20, M S_{\mathrm{e}}=6.50, p<.01 ; F_{2}(1\right.$, $\left.59)=10.90, M S_{\mathrm{e}}=2.89, p<.01\right)$. Similarly, there were more errors in the gender-incongruent $(8.9 \%)$ than in the gender-congruent condition $(7.8 \%)$, but this effect was not significant $\left(F_{1}(1,25)=2.64, M S_{\mathrm{e}}=5.54\right.$, n.s.; $F_{2}(1$, $\left.59)=3.71, M S_{\mathrm{e}}=1.71, p=.06\right)$. Most importantly, singular targets yielded more errors in the gender-in-

\footnotetext{
${ }^{7}$ Previous experiments (Schiller \& Caramazza, 2002) revealed that this effect is probably due to the fact that the distractor word interferes visually more with the presentation of a single picture (i.e., in the singular condition) than with the presentation of two identical pictures of the same object (i.e., in the plural condition). Except for Exp. 1a, this effect was found in all other experiments that involved a plural condition.
}

congruent $(11.0 \%)$ than in the gender-congruent condition $(8.8 \%)$, whereas in the plural there was no such difference $(6.9 \%$ vs. $6.7 \%$, respectively). Analyses of simple effects revealed that this effect was significant in the singular $\left(F_{1}(1,25)=6.26, M S_{\mathrm{e}}=5.12, \quad p<.05\right.$; $\left.F_{2}(1,59)=6.57, M S_{\mathrm{e}}=2.68, p<.05\right)$, but not in the plural (both $F$ 's $<1$ ). However, there was no interaction between Number of Target and Gender Condition $\left(F_{1}(1\right.$, $25)=1.80, \quad M S_{\mathrm{e}}=5.12, \quad$ n.s.; $F_{2}(1,59)=1.95, M S_{\mathrm{e}}=$ 2.06, n.s.).

\section{Discussion}

The results of Experiments 1a-c are interesting for several reasons. First, Experiments 1a and 1c demonstrate that the gender congruency effect is also a stable phenomenon in German. Schriefers (1993) obtained the original gender congruency effect in Dutch, a language with two genders. Recently, Schriefers and Teruel (2000) investigated the gender congruency effect in German, a language with a three-gender system. Their second experiment was similar to (part of) our Experiment 1a. Participants named pictures using a Det $+\mathrm{N}$ phrase while they where presented with auditory distractor words. Schriefers and Teruel (2000) obtained a gender congruency effect at SOA $+75 \mathrm{~ms}$. Here, we replicate this gender congruency effect in German at SOA $0 \mathrm{~ms}$ with visual distractors. As can be seen in Table 1, the gender congruency effect was similar for all three genders, as reflected by the absence of an interaction between the gender of the target and the Gender Condition $\left(F_{1}(2,52)=2.33, M S_{\mathrm{e}}=630.85\right.$, n.s.; $\left.F_{2}(2,38)<1\right)$.

When colored objects were named using the appropriate determiner in a determiner-adjective-noun phrase in Experiment 1c, there was again a gender congruency effect in the singular, but not in the plural. In the singular, a selection between three free-standing phonological forms has to be made (i.e., der, die, or das), whereas in the plural there is only one determiner form, namely die. The results of Experiment 1c mirror the outcome of Experiment 1a (Det-NP naming) and support the DSIH of the gender congruency effect. These results again resemble Schriefers and Teruel's (2000) data for German singular targets. In their first experiment, participants named a set of colored pictures using a Det + Adj + N phrase such as der rote Hammer ('the red hammer') while hearing a distractor word. At SOA $+150 \mathrm{~ms}$ they found a gender congruency effect. In the present experiment, we find a similar effect at SOA $0 \mathrm{~ms}$ with visual distractors.

However, Experiment $1 \mathrm{~b}$ did not show a gender congruency effect. This is in contrast to what Schriefers (1993, Experiment 2) found in Dutch. How can this difference in results be accounted for? One reason may be that gender agreement for adjectives, but not for determiners, involves the affixation of a bound 
morpheme. This means that the initial part of the adjective, i.e., the stem, in an $\mathrm{Adj}+\mathrm{N}$ phrase is the same for different genders (e.g., roter ${ }_{\text {mas }} \mathrm{Tisch}_{\text {mas }}$ 'red table' vs. rote $_{\text {fem }}$ Wand $_{\text {fem }}$ 'red wall' vs. rotes $_{\text {neu }} B$ uch $_{\text {neu }}$ 'red book'). One possible implication of this fact is that since gender-suffixed variants of an adjective differ at the end of the word any effects of competition in the selection of affixes is not measurable with the currently used paradigms. Perhaps participants prepare for production of the adjective stem and begin speaking as soon as they have enough information about the noun, thereby masking any effects of competition that may occur in the selection of the gender-marked suffix. The other possibility is that the selection of morphophonological processes, unlike that of free-standing morphemes and stems, is not a competitive process but an automatic consequence of specific grammatical properties. However, before we can consider further these possibilities we must first confirm the reliability and generalizability of our results. This is important because Schriefers (1993) found a gender congruency effect with Adj + N phrases in Dutch (groen $_{\text {neu }}$ boek $_{\text {neu }}$ 'green book' vs. groene $_{\text {com }}$ tafel $_{\text {com }}$ 'green table'). The difference in results between the two studies remains unresolved, and it could reflect differences between languages - German versus Dutch. This explanation is unlikely to be the correct one since recently Costa et al. (submitted) were also unable to find a gender congruency effect in Croatian when participants were asked to produce gender-marked possessive $\mathrm{Adj}+\mathrm{N}$ phrases (moj $\mathrm{krevet}_{\text {masc }}$ [my bed]; moja truba $_{\text {fem }}$ [my trumpet]), but did find a congruency effect when the noun's gender triggered the selection of a free-standing morpheme (the pronouns $\mathrm{ga}_{\text {mas }}\left[{ }^{\mathrm{it}} \mathrm{it}_{\mathrm{mas}}\right.$ '] $\mathrm{je}_{\mathrm{fem}}$ [ $\left.\left.{ }^{i} t_{\text {fem }}{ }^{\prime}\right]\right)$. Nonetheless, it is important to first establish reliably that the gender congruency effect is not found in the production of NPs in which the gender-marked elements are purely inflectional features and not freestanding morphemes or stems. We will address this issue in Exp. 4b with Dutch materials.

Second, our results go beyond Schriefers' (1993) and Schriefers and Teruel's (2000) results because they show that the gender congruency effect only occurs when pictures are named with their corresponding determiner in the singular but not in the plural. In the singular, the appropriate gender-marked determiner has to be selected from a set of three different determiners, whereas in the plural the determiner is the same for all three genders. Thus our results suggest that the putative gender congruency effect may actually be a determiner congruency effect, as suggested by Miozzo and Caramazza (1999). According to this account, the interference effect that is observed in Dutch and German occurs not in selecting the gender of the target noun but in selecting the gender-appropriate determiner. In the gender-incongruent condition, different forms of determiners compete for selection in the singular, resulting in an interference effect. In the plural, however, the determiner is the same for all three genders and thus no interference occurs.

We now turn to the issue of how the number feature of the distractor affects the selection of the determiner of the target noun. Recall that in this experiment distractors were always in the singular. If the number of the distractor played a role in determiner selection we would expect that the distractors would activate their corresponding singular determiners, der, die, or das. Therefore, in the plural condition, i.e., when the determiner die is required for the target, we should have obtained significantly faster RTs when the distractor word is feminine (a die word) than when it is masculine or neuter (a der or a das word, respectively). In contrast, if the number feature of the distractor is not a candidate for insertion in the determiner frame-because the determiner's number feature is set by the extra-lexical context defined by the number of objects in the picture-, we would not expect differences between the different distractor genders in the plural. In this case, the number features selected for the determiner frame would always be plural which would activate the determiner form die, independently of the gender of the distractor word. Since plural targets also require the determiner die, there would never be a mismatch in the plural. Earlier evidence on the selection of number features (Schiller \& Caramazza, 2002) supports this latter view.

To be able to distinguish between these two possibilities, we re-analyzed the data according to the gender of the distractor word. As can be seen in Tables 4 and 5, there are no differences between the individual distractor conditions: In Experiment 1a, naming latencies to plural targets are not significantly faster with feminine distractors $(763 \mathrm{~ms})$ than with masculine $(757 \mathrm{~ms})$ or neuter $(764 \mathrm{~ms})$ distractors $\left(F_{1}(2,52)=1.35, M S_{\mathrm{e}}=863.60\right.$, n.s.; $F_{2}(1,57)=1.15, M S_{\mathrm{e}}=614.37$, n.s.). For masculine plural targets, naming latencies are not faster when the distractor is feminine $(760 \mathrm{~ms})$ than when it is masculine or neuter $\left(773\right.$ or $767 \mathrm{~ms}$, respectively) $\left(F_{1}(2,52)<1\right.$; $\left.F_{2}(1,57)<1\right)$, and for feminine $\left(F_{1}(2,52)=2.02, M S_{\mathrm{e}}=\right.$ 867.04, n.s.; $\left.F_{2}(1,57)<1\right)$ and neuter $\left(F_{1}(2,52)=1.30\right.$, $M S_{\mathrm{e}}=1412.93$, n.s.; $F_{2}(1,57)=3.45, \quad M S_{\mathrm{e}}=1101.44$, n.s.) targets this is also the case. In Experiment 1c, the differences between the distractor genders are only minimal and insignificant (see Table 5). Most importantly, feminine distractors $(716 \mathrm{~ms})$ do not lead to faster RTs in the plural than masculine $(715 \mathrm{~ms})$ or neuter $(711 \mathrm{~ms})$ distractors $\left(F_{1}(2,50)<1 ; F_{2}(1,57)<1\right)$. This true for feminine targets $\left(F_{1}(2,50)=1.13, M S_{\mathrm{e}}=1441.67\right.$, n.s.; $\left.F_{2}(1,57)<1\right)$, for masculine targets $\left(F_{1}(2,50)<1\right.$; $\left.F_{2}(1,57)<1\right)$, and for neuter targets $\left(F_{1}(2,50)<1\right.$; $F_{2}(1,57)=2.95, M S_{\mathrm{e}}=931.64$, n.s.). These results support the view that the number feature of the distractor is set independently of the number information in the distractor word. The number feature of the distractors is 
Table 4

Mean naming latencies (in ms) for plural targets in Experiment 1a split by the gender of the distractor word (German Det + Noun naming)

\begin{tabular}{lccccc}
\hline Gender of Distractor & \multicolumn{3}{c}{ Mean } & \multicolumn{3}{c}{ Gender of Target } & Neuter \\
\cline { 2 - 5 } & Feminine & Masculine & 777 & 763 \\
\hline Feminine & 750 & 760 & 768 & 757 \\
Masculine & 736 & 773 & 778 & 764 \\
Neuter & 744 & 767 & & \\
\hline
\end{tabular}

Table 5

Mean naming latencies (in $\mathrm{ms}$ ) for plural targets in Experiment 1c split by the gender of the distractor word (German Det + Adj + Noun naming)

\begin{tabular}{lcccc}
\hline Gender of Distractor & \multicolumn{2}{c}{ Mean } & \multicolumn{2}{c}{ Mender of Target } \\
\cline { 2 - 4 } & Feminine & Masculine & Neuter & 716 \\
\hline Feminine & 718 & 715 & 716 & 715 \\
Masculine & 707 & 726 & 712 & 712 \\
Neuter & 704 & 716 & 711 & \\
\hline
\end{tabular}

not considered for insertion in the determiner frame for NP production. Instead, number features in our task are selected on the basis of extra-lexical, contextual factors; i.e., the number of objects in the picture. An important implication is that we need not consider the number of the distractor in investigating the effects of gender congruency on determiner selection. Nonetheless, we reconsider this issue in Experiment 3 where we empirically assess this claim.

The results obtained for German in Experiments 1a-c do not support the GSIH. Instead, the experimental outcome so far supports the alternative DSIH. The original experiments by Schriefers (1993) were carried out in Dutch, although Schriefers and Teruel (2000) recently replicated the gender congruency effect for German. However, these authors tested only singular targets. In Experiments $2 \mathrm{a}$ and $2 \mathrm{~b}$ we re-examined the gender congruency effect in Dutch with both singular and plural NPs. As already noted, the Dutch determiner system is similar to the German one in that different determiners are associated with different genders in the singular, but not in the plural. The determiner de is used for common gender and het for neuter gender, as for instance in de tafel ('the table,' com) or het boek ('the book,' neu). In the plural, only one determiner is used for both genders, namely de, as in de tafels ('the tables,' com) or de boeken ('the books,' neu). If there is a genuine gender congruency effect in Dutch, this effect should be found both in the singular and in the plural NP conditions. However, if the putative gender congruency effect is really a determiner congruency effect, it should only be obtained for singular NPs, just as in German.

In his experiments, Schriefers (1993) also varied the SOA between picture onset and the presentation of the distractor word. The motivation for this manipulation was to ensure that the distractor word's gender feature was activated near the point in time at which the target word's gender feature was being selected. In other words, it is possible that the effect of gender congruency might depend on SOA. When the distractor is presented too early with respect to picture onset, the activation of an incongruent gender feature may have already decayed and thus would be too weak to influence the selection of the target's gender node. When the distractor is presented too late, the gender of the target word may have already been selected and therefore immune to the activation of an incongruent gender feature. Indeed, Schriefers (1993) obtained the largest gender congruency effect at SOA $0 \mathrm{~ms}$. The effect was only half as large at SOA $-200 \mathrm{~ms}$ in his Experiment 1 and at SOA $+450 \mathrm{~ms}$ no significant congruency effect was found. In his Experiment 2, the gender congruency effect was only significant at SOA $0 \mathrm{~ms}$. Since this is the SOA at which the semantic interference effect is usually obtained, this was taken as evidence that the gender congruency effect occurs at the same level as the semantic interference effect, i.e., the lexical node level. We tested three different SOAs in Experiment 2a, namely $-100 \mathrm{~ms}, 0 \mathrm{~ms}$, and $+100 \mathrm{~ms}$ to maximize the probability of getting a gender congruency effect. Experiment $2 b$ was run with only one SOA, i.e., $0 \mathrm{~ms}$.

\section{Experiments 2a and 2b: Noun phrase production in Dutch}

In these experiments, native Dutch participants were asked to name a set of pictures paired with a gendercongruent and a gender-incongruent distractor word. Pictures could either appear as single objects (singular condition) or as two identical objects (plural condition) (Exp. 2a). Alternatively, pictures appeared only as single objects and a low or high tone indicated singular or 
plural condition (Exp. 2b). Participants were asked to name the picture with the appropriate determiner in Dutch, e.g., het boek ('the book') or de boeken ('the books'). Experiment 2a is a replication of Experiment 1a in Dutch.

There is, however, one potential problem with Experiment 2a (as was noted for Experiments 1a and 1c). It could be argued that as soon as participants detected that two objects were presented they automatically selected the determiner de (without further consideration of the target's gender) and started to produce their response. By doing so, the gender-incongruent distractor did not get a chance to interfere with the selection of the picture's name gender specification in the plural condition. To obtain positive evidence that gender properties of the distractor word are being processed and affect the selection/production of the target noun we conducted a control experiment in which only single objects were shown on the screen together with the distractor word and only afterwards were participants cued about whether to produce a singular or a plural NP (Experiment 2b).

\section{Method}

\section{Participants}

Eighteen Dutch students from the University of Maastricht took part in Experiment 2a. In Experiment 2b, 18 Dutch students from the pool of participants of the Max Planck Institute for Psycholinguistics in Nijmegen participated. All participants were paid for their participation and none of them took part in more than one experiment.

\section{Materials}

Twenty-two target pictures corresponding to monomorphemic Dutch nouns were selected for naming. According to Deutsch and Wijnen (1985) the two genders in Dutch are "independent of the phonetic form and meaning of the noun." (p. 794) Each target picture was paired with a gender-congruent and a gender-incongruent distractor word. Distractor words were phonologically and semantically unrelated to the picture names. A complete list of target pictures and distractor words can be found in Appendix B. Pictures were simple black line drawings of everyday objects presented on white background. They were taken from the pool of pictures of the Max Planck Institute for Psycholinguistics in Nijmegen. Distractor words were displayed without determiners in their singular forms as black characters (font type and size: Geneva, 30 pts) in, across, or between the object(s). Pictures were presented in the center of the screen with the distractor words appearing at different positions around fixation. For an individual picture, however, the distractor words appeared in the same position.

\section{Procedure}

The procedure for Experiment 2a was the same as in Experiment 1a. In Experiment 2b, we used a slightly different procedure. Participants saw on each trial a picture of one object superimposed by a gendercongruent or a gender-incongruent distractor word on the screen. After $300 \mathrm{~ms}$, they heard a tone indicating whether the target was to be produced in the singular (low tone) or in the plural (high tone). Depending on the tone (low or high) they had to name the object with the appropriate determiner in the singular or in the plural. Since participants only knew $300 \mathrm{~ms}$ after target and distractor onset whether a singular or a plural had to be produced, they could not prepare the appropriate determiner upon perceiving the picture. However, $300 \mathrm{~ms}$ is long enough to allow them to recognize and process the distractor word. The presentation of the trial sequences, which were otherwise identical to Exp. 2a, was controlled by NESU (Nijmegen Experimental Set-Up).

\section{Design}

As in the previous experiments, there were three parts in Experiments 2a and 2b: a familiarization phase, a practice phase, and a naming phase. The procedure of the familiarization phase was identical to the familiarization phase in Experiments 1a-c. In the practice phase, every picture had to be named once in the singular and once in the plural using the appropriate picture names preceded by the appropriate determiner to make sure participants knew the correct gender of the stimuli. The order of the trials was randomized for each participant individually. After the completion of the practice block, the experimenter corrected the participants in the rare event that they used an inappropriate picture name. ${ }^{8}$

In Experiment 2a, the naming phase consisted of three blocks, one for each SOA. In Experiment 2b, only SOA $0 \mathrm{~ms}$ was tested. Within one SOA, all pictures were tested in all conditions ( 22 pictures $\times 2$ number conditions $\times 2$ gender congruency conditions equals 88 trials).

\footnotetext{
${ }^{8}$ The practice phase of Experiment 2a was similar to Experiment 1 by Janssen and Caramazza (in press), i.e., Det-NP naming in Dutch without distractors. Janssen and Caramazza found an interaction between gender and number of the target. Neuter Det-NPs showed a cost from singular to plural, whereas this was not the case for common gender Det-NPs. They argued that their result indicates that the gender feature is also selected in the plural when it would be logically unnecessary. We obtained similar results in the practice blocks of Exp. 2a here with different materials: Neuter plural Det-NPs showed a cost of $21 \mathrm{~ms}$ compared to the singular, whereas common gender plural NPs were $12 \mathrm{~ms}$ faster than the respective singular NPs (neu, sg: $682 \mathrm{~ms}$; neu, pl: $703 \mathrm{~ms}$; com, sg: $692 \mathrm{~ms}$; com, pl: 680 $\mathrm{ms})$. The interaction between gender and number was not significant, however $\left(F_{1}(1,17)=3.25, M S_{\mathrm{e}}=1892.11\right.$, n.s.; $F_{2}(1,20)=1.24, M S_{\mathrm{e}}=2057.68$, n.s. $)$.
} 
There was a pause between each naming block. The order of the blocks was varied in Experiment 2a across participants and the blocks were randomized individually for each participant with the same constraints as in Experiment 1a. Experiment 2a was approximately 40 min long and Experiment $2 \mathrm{~b}$ took about $30 \mathrm{~min}$.

\section{Results}

Naming latencies shorter than $350 \mathrm{~ms}$ and longer than $1500 \mathrm{~ms}$ were counted as outliers (Exp. 2a: 2.0\% of the data; Exp. $2 b: 3.0 \%$ of the data). The data of one participant from Exp. 2a had to be excluded due to voice key malfunction. The mean naming latencies and error rates are summarized in Tables 6 and 7. Analyses of variance were run with Number of Target (singular or plural), Gender Condition (congruent or incongruent), and (in Exp. 2a) SOA ( $-100 \mathrm{~ms}, 0 \mathrm{~ms}$, or $+100 \mathrm{~ms})$ as independent variables. Separate analyses were carried out with participants $\left(F_{1}\right)$ and items $\left(F_{2}\right)$ as random variables.

\section{Experiment $2 a$}

Overall, error rates were extremely low $(<1 \%)$ and therefore not analyzed. Pictures were named slower in the singular $(716 \mathrm{~ms})$ than in the plural condition $(670 \mathrm{~ms})$. This $46 \mathrm{~ms}$ advantage was significant by participants and items $\left(F_{1}(1,16)=68.39, M S_{\mathrm{e}}=1543.83\right.$, $\left.p<.001 ; \quad F_{2}(1,21)=265.84, M S_{\mathrm{e}}=518.09, \quad p<.001\right)$ (see Footnote 6 for a possible account). In the gendercongruent condition, pictures were named $17 \mathrm{~ms}$ faster $(685 \mathrm{~ms})$ than in the gender-incongruent condition $(702 \mathrm{~ms})$. This main effect of Gender Condition was significant as well $\left(F_{1}(1,16)=22.10, M S_{\mathrm{e}}=651.04, p<\right.$ $\left..001 ; F_{2}(1,21)=12.55, M S_{\mathrm{e}}=1527.31, p=.001\right)$. Pictures were named approximately equally fast at SOA $-100 \mathrm{~ms}(680 \mathrm{~ms})$ as at SOA $0 \mathrm{~ms}(702 \mathrm{~ms})$ and at SOA $+100 \mathrm{~ms}(697 \mathrm{~ms})$. The effect of SOA was only significant by items but not by participants $\left(F_{1}(2,32)=1.71\right.$, $M S_{\mathrm{e}}=5027.21$, n.s.; $F_{2}(2,42)=6.48, M S_{\mathrm{e}}=1727.23$, $p<.01)$. SOA did not interact with Number of Target $\left(F_{1}(2,32)=2.63, M S_{\mathrm{e}}=776.13\right.$, n.s.; $F_{2}(2,42)=2.80$, $M S_{\mathrm{e}}=921.53$, n.s.) nor with Gender Condition $\left(F_{1}(2,32)=1.06, \quad M S_{\mathrm{e}}=710.51, \quad\right.$ n.s.; $\left.\quad F_{2}(2,42)<1\right)$. Most importantly, however, the interaction between Gender Condition and Number of Target was significant $\left(F_{1}(1,16)=11.18, M S_{\mathrm{e}}=555.94, p<.01 ; F_{2}(1,21)\right.$ $\left.=8.72, M S_{\mathrm{e}}=949.20, p<.01\right)$. As can be seen in Table 6 , the relative cost in the gender-incongruent condition as compared to the gender-congruent condition was

Table 6

Mean naming latencies (in ms) and percentage errors (in parentheses) in Experiment 2a (Dutch Det + Noun naming with three SOAs)

\begin{tabular}{|c|c|c|c|c|c|}
\hline \multirow[t]{2}{*}{ SOA } & \multirow{2}{*}{$\begin{array}{c}\text { Number of } \\
\text { Target }\end{array}$} & \multirow{2}{*}{$\begin{array}{l}\text { Gender } \\
\text { Condition }\end{array}$} & \multicolumn{2}{|c|}{ Gender of Target } & \multirow[t]{2}{*}{ Mean } \\
\hline & & & Common & Neuter & \\
\hline \multicolumn{6}{|c|}{$-100 \mathrm{~ms}$} \\
\hline & Singular & & & & \\
\hline & & Congruent & $696(1.1)$ & $682(0.0)$ & $689(0.5)$ \\
\hline & & Incongruent & 714 (1.6) & $696(1.1)$ & $705(1.3)$ \\
\hline & Plural & & & & \\
\hline & & Congruent & $664(0.0)$ & $663(0.5)$ & $663(0.3)$ \\
\hline & & Incongruent & $658(0.5)$ & $671(1.1)$ & $665(0.8)$ \\
\hline \multicolumn{6}{|l|}{$0 \mathrm{~ms}$} \\
\hline & Singular & & & & \\
\hline & & Congruent & $722(1.1)$ & $700(0.5)$ & $711(0.8)$ \\
\hline & & Incongruent & $745(0.0)$ & $740(1.6)$ & $742(0.8)$ \\
\hline & Plural & & & & \\
\hline & & Congruent & $669(0.5)$ & $674(0.0)$ & $671(0.3)$ \\
\hline & & Incongruent & $689(0.5)$ & $675(0.0)$ & $682(0.3)$ \\
\hline \multicolumn{6}{|c|}{$+100 \mathrm{~ms}$} \\
\hline & Singular & & & & \\
\hline & & Congruent & $711(2.7)$ & $701(3.2)$ & $706(2.9)$ \\
\hline & & Incongruent & $741(3.2)$ & $743(0.5)$ & $742(1.9)$ \\
\hline & Plural & & & & \\
\hline & & Congruent & $671(0.5)$ & $665(0.0)$ & $668(0.3)$ \\
\hline & & Incongruent & $676(0.0)$ & $672(2.7)$ & $674(1.3)$ \\
\hline
\end{tabular}


Table 7

Mean naming latencies (in ms) and percentage errors (in parentheses) in Experiment $2 b$ (Dutch Det + Noun naming with auditory cue)

\begin{tabular}{|c|c|c|c|c|}
\hline \multirow[t]{2}{*}{ Number of Target } & \multirow[t]{2}{*}{ Gender Condition } & \multicolumn{2}{|c|}{ Gender of Target } & \multirow[t]{2}{*}{ Mean } \\
\hline & & Common & Neuter & \\
\hline \multicolumn{5}{|l|}{ Singular } \\
\hline & Congruent & 755 (15.9) & $742(14.8)$ & $749(15.3)$ \\
\hline & Incongruent & $773(16.7)$ & $765(15.1)$ & 769 (15.9) \\
\hline \multicolumn{5}{|l|}{ Plural } \\
\hline & Congruent & $719(14.3)$ & $741(13.0)$ & $730(13.6)$ \\
\hline & Incongruent & $725(15.6)$ & $731(12.7)$ & $728(14.2)$ \\
\hline
\end{tabular}

always larger in the singular than in the plural. This effect was not modulated by SOA, as reflected by the absence of a triple interaction between SOA, Gender Condition, and Number of Target $\left(F_{1}(2,32)<1\right.$; $\left.F_{2}(2,42)<1\right)$.

Analyses of simple effects showed that the effect of Gender Condition was significant in the singular condition independent of SOA (SOA - $100 \mathrm{~ms}: F_{1}(1,16)=9.42$, $M S_{\mathrm{e}}=252.58, p<.01 ; F_{2}(1,21)=6.00, M S_{\mathrm{e}}=497.53, p$ $<.05$, SOA 0 ms: $F_{1}(1,16)=9.43, M S_{\mathrm{e}}=858.62, p<.01$; $F_{2}(1,21)=6.29, M S_{\mathrm{e}}=1725.55, p<.05, \mathrm{SOA}+100 \mathrm{~ms}:$ $F_{1}(1,16)=16.87, M S_{\mathrm{e}}=650.37, \quad p<.01 ; \quad F_{2}(1,21)=$ $\left.6.23, M S_{\mathrm{e}}=2397.38, p<.05\right)$ but not in the plural (SOA $-100 \mathrm{~ms}: F_{1}(1,16)<1 ; F_{2}(1,21)<1$, SOA $0 \mathrm{~ms}: F_{1}(1,16)$ $=1.98, M S_{\mathrm{e}}=424.43$, n.s.; $F_{2}(1,21)=1.62, M S_{\mathrm{e}}=$ 747.53 , n.s., SOA +100 ms: $\left.F_{1}(1,16)<1 ; F_{2}(1,21)<1\right)$.

\section{Experiment $2 b$}

We replaced the data of four participants with the highest error rates $(>20 \%)$ by four new participants. One item (poes 'cat') was eliminated from the analyses due to too high error rates $(>30 \%)$. There were no effects in the error analyses. Pictures were named slower in the singular $(759 \mathrm{~ms})$ than in the plural condition $(729 \mathrm{~ms})$. This $30 \mathrm{~ms}$ advantage was significant by participants and items $\left(F_{1}(1,17)=8.55, M S_{\mathrm{e}}=4517.95, p<.01\right.$; $\left.F_{2}(1,20)=30.34, M S_{\mathrm{e}}=659.42, p<.01\right)$. In the gender-congruent condition pictures were named $9 \mathrm{~ms}$ faster $(739 \mathrm{~ms})$ than in the gender-incongruent condition (748 $\mathrm{ms})$. The main effect of Gender Condition was marginally significant $\left(F_{1}(1,17)=6.47, M S_{\mathrm{e}}=411.26, p<.05\right.$; $\left.F_{2}(1,20)=3.20, M S_{\mathrm{e}}=625.32, p=.09\right)$. Most importantly, the interaction between Number of Target and Gender Condition was significant $\left(F_{1}(1,17)=10.28\right.$, $M S_{\mathrm{e}}=464.06, p<.01 ; F_{2}(1,20)=5.58, M S_{\mathrm{e}}=443.77$, $p<.05)$. Pictures were named $20 \mathrm{~ms}$ faster in the gendercongruent than in the gender-incongruent condition in the singular $\left(F_{1}(1,17)=21.50, M S_{\mathrm{e}}=338.70, p<.01\right.$; $\left.F_{2}(1,21)=10.97, M S_{\mathrm{e}}=407.01, p<.01\right)$ whereas in the plural the gender-incongruent condition was slightly faster than the gender-congruent condition (both $F$ 's $<1)$. This experiment replicates SOA $0 \mathrm{~ms}$ of Experiment $2 \mathrm{a}$ with a different task.

\section{Discussion}

The results of Experiments $2 \mathrm{a}$ and $2 \mathrm{~b}$ are very similar to those of Experiments 1a and 1c. The effect of a gender-incongruent distractor word in Dutch only yielded an interference effect when an object was named in the singular but not in the plural_just as in German. This effect was independent of whether the distractor was presented slightly before, simultaneously with, or slightly after target picture onset. In Dutch, there are two different determiners in the singular, which mark the gender of a noun (i.e., de for common gender or het for neuter gender). In the plural, however, there is only one determiner for both genders (i.e., de). If the gender congruency effect obtained in Experiment 2a genuinely reflected competition in selecting gender features, it should have been obtained independently of whether an object is named in the singular or in the plural. However, Experiments $2 \mathrm{a}$ and $2 \mathrm{~b}$ showed that genderincongruent distractors only had an effect in naming singular NPs, i.e., when different determiners compete for selection. No gender congruency effect was obtained in naming plural NPs where the same determiner is used for both genders and hence there is no competition in determiner selection. The results of Experiment $2 b$ are qualitatively similar to those of Experiment 2a. This shows that the distractor word is processed and exhibits an influence on the naming latencies of the target, even under conditions in which it is not immediately clear whether a singular or a plural has to be produced. Together with the results obtained in Experiments 1a and 1c, the outcome of Experiments $2 \mathrm{a}$ and $2 \mathrm{~b}$ strongly suggests that the gender congruency effect may be better characterized as a determiner congruency effect as suggested by Miozzo and Caramazza (1999).

As in the case of German, the assumptions about the activation and selection of the number feature of the distractor word are crucial for the DSIH in the plural condition. If the number feature of the distractor were a candidate for insertion in the determiner frame, we would expect faster naming latencies in the plural when the distractor has common gender (a de word) than when it has neuter gender (a het word). This is because 
plural targets always require the determiner de. If, however, the conceptual information about the target (one or two objects on the screen) establishes number feature selection independently, no differences would be expected in the plural condition between distractors of different genders. This is because plural targets (de targets) would select the number plural without consideration of the number feature of the distractor word and hence there would be no determiner incongruence in the plural. Table 8 shows that the latter scenario is the likely one: Naming latencies for plural targets are no faster when paired with common gender distractors as compared to neuter gender distractors $\left(F_{1}(1,16)<1\right.$; $\left.F_{2}(1,20)<1\right)$. This result once more supports the assumption that the number feature of the distractor does not play an independent role in the selection of the number feature of the determiner in our experiments. A similar argument could be put forward for Exp. $2 \mathrm{~b}$. However, as can be seen in Table 9, no advantage was found for common gender distractors over neuter ones in the plural $\left(F_{1}(1,17)=1.90, M S_{\mathrm{e}}=827.45\right.$, n.s.; $F_{2}(1,21)=2.24, M S_{\mathrm{e}}=994.41$, n.s. $)$.

\section{Experiment 3: Noun phrase production in Dutch with singular and plural distractors}

To this point we have established that the gender congruency effect in the picture-word interference task is found in the production of singular but not plural NPs in German and Dutch. This result is clearly incompatible with the assumption that grammatical feature selection is a competitive process (GSIH). The implications of this result for the hypothesis that gender congruency effects are really effects of determiner selection competition (DSIH) are not as clear. This is due to uncertainties about the way in which the number feature of the distractor word affects the selection of the target noun's determiner. We have argued that the process of selection of the number feature for determiner production considers only phrasal (extra-lexical) features and therefore the morphological information about number in the distractor word does not affect determiner selection. In Experiment 3, we address this issue directly. We

Table 8

Mean naming latencies (in ms) for plural targets in Experiment 2a split by the gender of the distractor word (Dutch Det + Noun naming with three SOAs)

\begin{tabular}{lccc}
\hline $\begin{array}{l}\text { Gender of } \\
\text { Distractor }\end{array}$ & \multicolumn{2}{c}{$\begin{array}{c}\text { Gender of } \\
\text { Target }\end{array}$} & Mean \\
\cline { 2 - 3 } & Common & Neuter & \\
\hline Common & 668 & 674 & 671 \\
Neuter & 673 & 667 & 670 \\
\hline
\end{tabular}

Table 9

Mean naming latencies (in ms) for plural targets in Experiment $2 \mathrm{~b}$ split by the gender of the distractor word (Dutch Det + Noun naming with auditory cue)

\begin{tabular}{lccc}
\hline \multirow{2}{*}{$\begin{array}{c}\text { Gender of } \\
\text { Distractor }\end{array}$} & \multicolumn{2}{c}{$\begin{array}{c}\text { Gender of } \\
\text { Target }\end{array}$} & Mean \\
\cline { 2 - 3 } & Common & Neuter & \\
\hline Common & 667 & 675 & 671 \\
Neuter & 671 & 681 & 676 \\
\hline
\end{tabular}

systematically test whether or not the number feature of the distractor word contributes to the selection of the target determiner by completely crossing the factors Gender (congruent vs. incongruent) and Number (singular vs. plural) between targets and distractors. If the number features of the distractor words are considered for insertion in the determiner frame (in addition to their gender features), the following pattern of results (for Dutch) should be obtained in the context of the DSIH. When targets are singular (de or het) and distractors are singular (de or het), the standard congruency effect (see Experiments $2 \mathrm{a}$ and $2 \mathrm{~b}$ ) should be found. However, when targets are singular (de or het) and distractors are plural (de), only neuter gender targets (het) should show interference. In contrast, when both targets and distractors are plural (de), no effect of congruency should be visible. But when targets are plural (de) and distractors are singular (de or het), interference should be found, but only with neuter gender distractors (het).

Alternatively, if the number feature of the distractor word plays no role in determiner selection, the following scenario is predicted: There should be no gender congruency effects in plural NP production irrespective of the number of the distractor. As discussed in the Introduction, this prediction follows from the fact that in plural NP production the same determiner is used for all genders and therefore there can be no determiner competition. To test these predictions, we ran a replication of Experiment 2a including singular as well as plural distractors.

\section{Method}

\section{Participants}

Twenty-six native Dutch participants from the pool of participants of the Max Planck Institute for Psycholinguistics in Nijmegen took part in Experiment 3 in exchange for pay. None had participated in the previous experiments.

\section{Materials}

The materials were the same as in Experiments 2a and $2 b$, except that an equal number of distractors morphologically marked for plural was added. 


\section{Procedure}

The procedure was the same as in Experiment 2a, except that the trial presentation was controlled by NESU.

\section{Design}

The design was similar to Experiment 2a. However, there was only one SOA, namely $0 \mathrm{~ms}$, in Experiment 3. The naming phase consisted of two blocks. There was a total of 176 pictures $(22$ pictures $\times 2$ target numbers $\times 2$ gender conditions $\times 2$ distractor numbers). The order of blocks was varied across participants and there was a short break between each naming block. The whole experiment lasted approximately $45 \mathrm{~min}$.

\section{Results}

Naming latencies shorter than $350 \mathrm{~ms}$ and longer than $1200 \mathrm{~ms}$ were counted as outliers $(3.0 \%$ of the data). The mean naming latencies and error rates are summarized in Table 10. Analyses of variance were run with Number of Target (singular or plural), Gender Condition (congruent or incongruent), and Number of Distractor (singular or plural) as independent variables. Separate analyses were carried out with participants $\left(F_{1}\right)$ and items $\left(F_{2}\right)$ as random variables.

The main effect of Number of Target was significant $\left(F_{1}(1,25)=102.67, M S_{\mathrm{e}}=1066.07, p<.01 ; F_{2}(1,21)=\right.$ 90.08, $\left.M S_{\mathrm{e}}=1102.20, p<.01\right)$. Pictures were named $47 \mathrm{~ms}$ faster in the plural condition $(611 \mathrm{~ms})$ than in the singular condition $(658 \mathrm{~ms})$. Number of Distractor did not have an effect (both $F \mathrm{~s}<1$ ). The effect of Gender Congruency was significant $\left(F_{1}(1,25)=10.32\right.$,
$M S_{\mathrm{e}}=356.11, p<.01 ; F_{2}(1,21)=8.05, M S_{\mathrm{e}}=492.56$, $p<.01)$. Most importantly, however, the interaction between Gender Congruency and Number of Target was significant $\quad\left(F_{1}(1,25)=7.75, M S_{\mathrm{e}}=703.88, \quad p<.05\right.$; $\left.F_{2}(1,21)=12.91, M S_{\mathrm{e}}=499.60, p<.01\right)$. This interaction reflects the fact that incongruent gender between target and distractor led to interference in the singular, whereas it had no effect in the plural, independent of the Number of Distractor (see Table 10). The triple interaction between Number of Distractor, Number of Target, and Gender Congruency was not significant (both $F$ s $<1$ ), suggesting that there were no differences in effects whether the distractor word was singular or plural.

Analyses of simple effects showed that Gender Congruency had a significant effect for singular targets when the distractors were also in the singular $\left(F_{1}(1,25)=6.93\right.$, $M S_{\mathrm{e}}=630.14, p<.05 ; F_{2}(1,21)=8.34, M S_{\mathrm{e}}=545.75$, $p<.01)$ and when distractors were in the plural $\left(F_{1}(1\right.$, $25)=6.51, M S_{\mathrm{e}}=915.18, p<.05 ; F_{2}(1,21)=5.73, M S_{\mathrm{e}}$ $=784.56, p<.05)$. For plural targets, Gender Congruency did not yield any significant results whether distractors were in the singular (both $F \mathrm{~s}<1$ ) or in the plural (both $F$ s $<1$ ).

\section{Discussion}

One half of Experiment 3 is a replication of SOA $0 \mathrm{~ms}$ of Experiment 2a: Targets were in the singular or in the plural and distractor words in the singular. The outcome of this half of the experiment replicates the findings of Experiment 2a, namely a gender congruency effect in the singular condition and no effect in the plural condition. This is an important result in itself because it replicates

Table 10

Mean naming latencies (in ms) and percentage errors (in parentheses) in Experiment 3 (Dutch Det + Noun naming with singular and plural distractors)

\begin{tabular}{|c|c|c|c|c|c|}
\hline \multirow[t]{2}{*}{ Number of Target } & \multirow[t]{2}{*}{ Number of Distractor } & \multirow[t]{2}{*}{ Gender Condition } & \multicolumn{2}{|c|}{ Gender of Target } & \multirow[t]{2}{*}{ Mean } \\
\hline & & & Common & Neuter & \\
\hline \multicolumn{6}{|l|}{ Singular } \\
\hline & Singular & & & & \\
\hline & & Congruent & $654(9.4)$ & $641(7.3)$ & $647(8.4)$ \\
\hline & & Incongruent & $676(17.8)$ & $661(11.2)$ & $668(14.5)$ \\
\hline & Plural & & & & \\
\hline & & Congruent & $662(15.4)$ & $634(8.0)$ & $647(11.7)$ \\
\hline & & Incongruent & $683(10.8)$ & $654(12.9)$ & $669(11.5)$ \\
\hline \multicolumn{6}{|l|}{ Plural } \\
\hline & Singular & & & & \\
\hline & & Congruent & $609(8.7)$ & 613 (4.9) & $611(6.8)$ \\
\hline & & Incongruent & $614(10.1)$ & $608(9.8)$ & $611(10.0)$ \\
\hline & Plural & & & & \\
\hline & & Congruent & $608(7.7)$ & $618(8.0)$ & $613(7.9)$ \\
\hline & & Incongruent & $614(5.2)$ & 603 (4.9) & $609(5.0)$ \\
\hline
\end{tabular}


previous findings with new participants tested in a different laboratory.

The other half of Experiment 3 shows that the number of the distractor plays no role in determiner selection in the picture-word naming task-only the gender of the distractor and the number of the target matter. This is shown clearly by the fact that plural distractors produced a gender congruency effect in singular but not plural NP production. This means the determiner selection process considers the gender but not the number features of competing nouns; in other words, the number feature is determined extra-lexically.

Two experiments in German and three experiments in Dutch have shown a congruency effect induced by gender-(in)congruent distractor words. However, this effect was only observed in the singular condition, i.e., when a gender-marked determiner had to be selected. In the plural condition, when there was only one determiner to choose from, no such effect was obtained. This shows that the occurrence of a congruency effect is contingent on whether or not there are multiple determiners to choose from. Furthermore, Experiment 3 has shown that the effect does not depend on the number (singular or plural) of the distractor word, suggesting that gender and number features are subject to different selection principles. Finally, Experiment $2 \mathrm{~b}$ excludes the possibility that participants responded with the appropriate determiner in the plural condition as soon as they saw two objects on the screen.

The results of our Experiment $1 \mathrm{~b}$ with German speakers are in conflict with those reported by Schriefers (1993) who obtained a gender congruency effect in an Adj $+\mathrm{N}$ naming experiment with Dutch speakers. In his Experiment 2, naming latencies for adjective-noun phrases were significantly slower when colored pictures were paired with a gender-incongruent as compared to gender-congruent distractor word. It is unclear what may be responsible for the different patterns of results. Therefore, we attempted to replicate Schriefers' second experiment in Experiment $4 \mathrm{a}$ of this study.

\section{Experiments 4a and 4b: Adj + N Noun phrase production in Dutch}

Experiment 4a was set up to replicate Schriefers' (1993) Experiment 2 as closely as possible. Native Dutch participants were asked to name a set of pictures paired with a gender-congruent and a gender-incongruent distractor word. Pictures were colored and appeared only as single objects. In Experiment $4 \mathrm{a}$, participants were asked to name the picture in the singular together with the appropriate color adjective in Dutch, e.g., rood boek /rot buk/ ('red book') or rode tafel /rodə taflə/ ('red table'). Schriefers obtained a gender congruency effect under these conditions. If the gender congruency effect in adjective-noun naming in Dutch is a real effect, we should be able to replicate it. In Experiment 4b, a different group of participants saw the same pictures but were asked to name them using a Det + Adj NP, e.g., het rode boek ('the red book') or de rode tafel ('the red table'). According to the determiner competition hypothesis (Caramazza, Miozzo, Costa, Schiller, \& Alario, 2001) we should observe a gender congruency effect in Experiment $4 b$, even if we do not observe such an effect in Experiment $4 \mathrm{a}$.

\section{Method}

\section{Participants}

Sixteen native Dutch participants from the pool of participants of the Max Planck Institute for Psycholinguistics in Nijmegen took part in Experiment 4a and 15 participants from the same population took part in Experiment $4 \mathrm{~b}$ in exchange for pay. None of them participated in any other experiment of this study.

\section{Materials}

Twenty-two target pictures corresponding to monomorphemic Dutch nouns were selected for naming. Half of them had common gender; the other half had neuter gender. The target pictures overlapped for the most part with the materials used by Schriefers (1993) and La Heij et al. (1998) and most of them were the same items used in the previous experiment. Each target picture was paired with a gender-congruent, a gender-incongruent, a phonologically, and a semantically related distractor word (see Appendix C for a complete list of target pictures and distractor words). In addition, there was a set of 32 filler pictures paired with gender-congruent, phonologically and semantically unrelated distractors. Pictures were simple line drawings of everyday objects presented on white background. They were taken from the picture database of the Max Planck Institute for Psycholinguistics in Nijmegen. Pictures were colored in red, green, blue, or purple. Distractor words were displayed as black characters (font type and size: Geneva, $30 \mathrm{pts}$ ) in or across the object. Pictures were presented in the center of the screen with the distractor words appearing around fixation.

\section{Procedure}

The procedure was similar to Experiment $1 \mathrm{~b}$ except that trial presentation was controlled by NESU.

\section{Design}

As in the previous experiments, there were three parts in Experiments 4a and 4b: a familiarization phase, a practice phase, and a naming phase. The familiarization phase was identical to the familiarization phase in Experiment $1 \mathrm{~b}$. In the practice phase, pictures first appeared in black on white and had to be named using the 
appropriate definite determiners and picture names. A second practice block followed, in which some randomly chosen objects appeared in color. Participants were required to name those colored objects using the appropriate gender-marked color adjective and name (Experiment $4 \mathrm{a}$ ) or using the appropriate definite determiner plus color adjective and name (Experiment $4 \mathrm{~b}$ ). The order of the trials in the familiarization and practice phases was randomized for each participant individually. After completion of the practice blocks, the experimenter corrected participants if they had used an inappropriate picture name.

The naming phase consisted of four blocks. In Experiment $4 \mathrm{a}$, participants named the colored objects using an $\mathrm{Adj}+\mathrm{N}$ NP, in Experiment $4 \mathrm{~b}$ they used a Det + Adj + N NP. All blocks had SOA 0 ms in Exp. 4b, whereas in Exp. 4a we ran two SOAs: One group of participants received all blocks with SOA $-100 \mathrm{~ms}$, a second group received them with SOA $0 \mathrm{~ms}$. Except for the filler pictures, all pictures were tested in all conditions $(22$ pictures $\times 4$ conditions $\times 4$ colors equals 352 trials +32 filler pictures $\times 4$ colors equals 480 trials altogether). There was a pause between each naming block. The order of blocks was varied across participants and the blocks were randomized individually for each participant with the same constraints as in the Experiment 1b (except that there was no plural condition in the present experiment). Both experiments lasted approximately for an hour each.
Results

Naming latencies shorter than $350 \mathrm{~ms}$ and longer than $1500 \mathrm{~ms}$ were counted as outliers (Exp. $4 \mathrm{a}: 2.4 \%$ of the data; Exp. 4b: $3.0 \%$ of the data). The mean naming latencies and error rates are summarized in Tables 11 and 12. Analyses of variance were carried out with Condition (gender-congruent, gender-incongruent, semantically related, or phonologically related) and-in Exp. $4 \mathrm{a}-\mathrm{SOA}(-100 \mathrm{~ms}$ or $0 \mathrm{~ms})$ as independent variable. Separate analyses were carried out with participants $\left(F_{1}\right)$ and items $\left(F_{2}\right)$ as random variables.

\section{Experiment $4 a$}

The main effect of SOA was only significant by items $\left(F_{1}(1,32)<1 ; F_{2}(1,21)=32.01, M S_{\mathrm{e}}=788.88, p<.01\right)$ and SOA did not interact with Condition (both $F \mathrm{~s}<1$ ). Therefore, the data from both SOAs were collapsed for further analyses. The main effect of Condition was significant $\quad\left(F_{1}(3,96)=6.52, \quad M S_{\mathrm{e}}=760.71, \quad p<.01\right.$; $\left.F_{2}(3,63)=6.02, M S_{\mathrm{e}}=583.76, p<.01\right)$. Pictures were named fastest in the phonologically related condition (725 ms), followed by the gender-incongruent (734 ms) and the gender-congruent $(738 \mathrm{~ms})$ conditions; the semantically related condition was slowest $(746 \mathrm{~ms})$. The difference between the gender-congruent and the genderincongruent condition was not significant (both $t \mathrm{~s}<1$ ). Nor was the difference between the gender-congruent and the semantically related condition significant

Table 11

Mean naming latencies (in ms) and percentage errors (in parentheses) in Experiment 4a (Dutch Adj + Noun naming with two SOAs)

\begin{tabular}{|c|c|c|c|c|}
\hline \multirow[t]{2}{*}{ SOA } & \multirow[t]{2}{*}{ Condition } & \multicolumn{2}{|c|}{ Gender of Target } & \multirow[t]{2}{*}{ Mean } \\
\hline & & Common & Neuter & \\
\hline \multicolumn{5}{|c|}{$-100 \mathrm{~ms}$} \\
\hline & Congruent & $741(8.0)$ & $751(5.6)$ & $746(6.8)$ \\
\hline & Incongruent & $746(8.1)$ & $747(7.4)$ & $747(7.8)$ \\
\hline & Semantically related & $758(10.6)$ & $756(10.1)$ & $757(10.4)$ \\
\hline & Phonologically related & $727(7.7)$ & $748(6.1)$ & $738(6.9)$ \\
\hline \multicolumn{5}{|l|}{$0 \mathrm{~ms}$} \\
\hline & Congruent & $730(9.2)$ & $727(7.2)$ & $728(8.9)$ \\
\hline & Incongruent & $728(9.5)$ & $713(8.0)$ & $720(8.7)$ \\
\hline & Semantically related & $745(12.5)$ & $720(9.4)$ & $732(10.9)$ \\
\hline & Phonologically related & $711(8.4)$ & $712(7.7)$ & $711(8.0)$ \\
\hline
\end{tabular}

Table 12

Mean naming latencies (in ms) and percentage errors (in parentheses) in Experiment 4b (Dutch Det + Adj + Noun naming)

\begin{tabular}{llll}
\hline \multirow{2}{*}{ Condition } & \multicolumn{2}{c}{ Gender of Target } & Mean \\
\cline { 2 - 3 } & Common & Neuter & $750(8.7)$ \\
\hline Congruent & $754(10.2)$ & $747(7.3)$ & $766(7.9)$ \\
Incongruent & $776(9.8)$ & $757(5.9)$ & $755(10.3)$ \\
Semantically related & $772(11.1)$ & $739(9.5)$ & $732(8.4)$ \\
Phonologically related & $741(9.7)$ & $724(7.1)$ & \\
\hline
\end{tabular}


$\left(t_{1}(33)=1.48, \quad S D=29.06, \quad\right.$ n.s.; $\quad t_{2}(21)=1.46$, $S D=25.95$, n.s.). However, the phonologically related condition yielded significantly faster naming latencies than the gender-congruent condition $\left(t_{1}(33)=2.78\right.$, $\left.S D=27.67, p<.01 ; t_{2}(21)=4.21, S D=14.91, p<.01\right)$, showing that the distractor words were processed.

\section{Experiment $4 b$}

A crucial result of this experiment is the significant effect of Condition $\left(F_{1}(1,14)=12.23, M S_{\mathrm{e}}=974.93\right.$, $\left.p<.01 ; F_{2}(1,20)=4.67, M S_{\mathrm{e}}=1697.74, p<.05\right)$ : Targets were named faster $(750 \mathrm{~ms})$ in the gender-congruent than in the gender-incongruent $(766 \mathrm{~ms})$ distractor word condition. This effect was significant by participants and marginally significant by items $\left(t_{1}(1,14)=2.65\right.$, $S D=20.89, \quad p<.05 ; \quad t_{2}(1,21)=2.02, \quad S D=39.576$, $p=.056)$. Again, the semantically related condition $(755 \mathrm{~ms})$ was not significantly different from the gendercongruent condition (both $t \mathrm{~s}<1$ ). However, as in Experiment $4 \mathrm{a}$, the phonologically related condition $(732 \mathrm{~ms})$ was significantly faster than the gender-congruent condition $\left(t_{1}(1,14)=2.43, S D=30.80, p<.05\right.$; $\left.t_{2}(1,21)=2.23, S D=36.85, p<.05\right)$.

\section{Discussion}

Experiment 4a replicated with Dutch materials the failure to obtain a gender congruency effect in the adjective-noun naming task in German (Exp. 1b). This outcome contrasts with the results reported by Schriefers (1993, Exp. 2). The materials used in Experiment 4a comprised a larger, though in part overlapping, set of pictures than Schriefers' (1993) study. Pictures were colored in the same way as in Schriefers' experiments, and the methodology was roughly the same, except that we included a phonologically related condition. In our experiment, two SOAs $(-100 \mathrm{~ms}$ and $0 \mathrm{~ms})$ were tested, including the SOA at which Schriefers (1993) obtained a significant gender congruency effect.

The fact that phonologically related distractors yielded significantly faster naming latencies than gendercongruent distractors shows that the distractor words were processed and had an effect. The reason for the absence of a semantic interference effect is not obvious, although the effect is somewhat unreliable. For instance, Schriefers (1993) did not obtain this effect in his Experiment 2 either. Note, however, that we did get a semantic interference effect using the same materials in an earlier experiment (Schiller \& Caramazza, unpublished).

The failure to obtain a gender congruency effect in Experiment 4a is not in line with the prediction that this effect originates in the competition of gender features during grammatical feature selection, but is fully consistent with the view that effects of gender congruency only occur when free-standing gender-marked morphemes have to be produced (Caramazza et al., 2001). According to the former prediction, but not to the latter, effects of gender congruency should be found when a gendermarked adjective has to be produced in an Adj + N NP. Such an effect was originally reported by Schriefers (1993). However, we have been unable to replicate the effect both in Dutch (Experiment 4a) and in German (Experiment 1b) - in both experiments no effect of gender congruency was found.

The results of Experiment 4b, in contrast, support the hypothesis that when a free-standing gender-marked morpheme, such as a determiner, has to be selected for NP production, a gender congruency effect is obtained. Note that a different group of participants was presented with the same target pictures in this experiment, the only difference being the instruction: participants in Experiment $4 \mathrm{~b}$ were required to use a gender-marked determiner with the Adj NP to name the pictures. The outcome of Experiment $4 \mathrm{~b}$ contrasts sharply with the outcome of Experiment 4a. This contrast is important because it shows that with the same materials the occurrence of the gendercongruency effect is only contingent on the format of the target utterance. Therefore, the results of Experiments 4a and $4 \mathrm{~b}$ are consistent with the view that effects of gender congruency reflect competition of free-standing phonological forms such as definite determiners but not bound morphemes such as suffixes.

\section{General discussion}

The GSIH predicts that a gender congruency effect should be observed in early selection languages, irrespective of the type of NP that must be produced. Early selection languages, such as German and Dutch, select the form of the determiner based on gender (and number and/ or case) information alone because the determiner form does not depend on the phonological context. In contrast, the DSIH predicts that a gender congruency effect should be obtained only for early selection languages and then only for certain types of NPs-those involving the selection of different determiner forms. These contrasting predictions were put to test in this study with German and Dutch speakers. Both languages have the interesting characteristic that different determiners are used for different genders in singular NPs but the same determiner form is used for all genders in plural NPs. If the DSIH is correct, we should observe a gender congruency effect for singular but not plural NP production; if the GSIH is correct, we should observe gender congruency effects both for singular and plural NP production. The results of Experiments 1a and 1c (German) and Experiments 2a, 2b, 3 , and $4 \mathrm{~b}$ (Dutch) support the DSIH: A gender congruency effect was found only for singular NP production and not for plural NP production, independent of the number specification of the distractor (Exp. 3). These results suggest that grammatical feature selection is a 
non-competitive process. That is, grammatical features automatically become available as part of the lexical node selection process (Caramazza et al., 2001). However, if the phonological realization of grammatical features results in different lexical forms, there is interference due to competition at the level of form selection.

We should note here that we have failed to replicate in German (Exp. 1b) and in Dutch (Exp. 4a) Schriefers' (1993) gender congruency effect with Dutch $\mathrm{Adj}+\mathrm{N}$ phrases. Costa et al. (submitted) have also failed to find a gender congruency effect for Adj + N NPs in Croatian. In these languages, the adjectives in $\mathrm{Adj}+\mathrm{N}$ phrases are gender-marked. Should not we have expected a congruency effect due to selection competition between gendermarked inflectional affixes? There are two possible reasons for why we would not expect a gender congruency effect for inflectional affixes. The first possibility is that, consistent with the DSIH, selection interference effects only occur for free-standing (such as determiners) but not bound morphemes (such as inflections). The second possibility is that since inflectional affixes must be "attached" to the end of adjective stems they would only be needed fairly late in the process of NP production. On this account, any competition between inflectional forms would be resolved before they would be needed for attachment to the adjective stem, and therefore invisible in the type of experiments we have carried out. Our results do not allow us to choose between these two possibilities. Most important for this discussion, however, is that the outcome of our Adj + N naming experiments is consistent with the DSIH, but not with the GSIH. Nonetheless, the reason why Schriefers (1993) found a gender congruency effect with Adj + N phrases in Dutch, but we have not found it in German or Dutch remains unresolved and will be tackled in future research.

Finally, it is important that congruency effects could be obtained even when the appropriate determiner could be prepared on the basis of the visual input alone (Exp. 2b). One could have argued that the reason a gender congruency effect was obtained in the singular but not in the plural was because participants selected the determiner (de or die in Dutch and German, respectively) as soon as they recognized that two objects were presented on the screen, and immediately initiated their responses by producing the determiner, leaving no time for the genderincongruent distractor word to interfere. Experiment $2 b$ demonstrated, however, that this was not the case. Effects of gender congruency were obtained even when participants could not prepare the appropriate determiner on the basis of non-lexically relevant visual input.

Taken together, the eight experiments reported in this study provide evidence against the GSIH. Our results suggest that grammatical feature selection is a noncompetitive process. That is, (stem-based) grammatical features automatically become available as part of the lexical node selection process. Our results further suggest that the gender congruency effect found in Dutch and German may actually be a determiner congruency effect, as predicted by the DSIH. The DSIH can also nicely account for another result reported in the literature. In two experiments, La Heij et al. (1998) found a gender congruency effect in Dutch when participants were required to produce singular, determiner-noun phrases. The effect was absent, however, in naming nouns without a determiner. The latter result has also been obtained with Italian speakers (Miozzo \& Caramazza, unpublished). Since no determiner has to be selected in the bare noun naming condition, the DSIH predicts no effect of gender congruency, consistent with the obtained results.

If the DSIH is the correct account of the gender congruency effect observed in Dutch, German, and Croatian, the effect has a further important implication for theories of speech production. The DSIH implies that the determiner form of the distractor word is activated even though the distractor lexical node itself is not selected for production (since it is never produced); otherwise there could not be interference at the level of determiner selection. That is, interference arises because of the following set of events: (1) the distractor noun's gender feature is activated, (2) it sends activation to its determiner form, and (3) the activated form competes for selection with the determiner form of the target noun. However, this scenario of how determiner selection interference arises presupposes cascaded processing of information from the level where grammatical features are specified to the level of word form encoding. Discrete serial stage models (e.g., Levelt et al., 1999), which claim that only the word forms of the selected lexical nodes are encoded, are not compatible with the DSIH, and hence cannot account for the pattern of determiner selection interference in NP production in Dutch and German (and pronoun production in Croatian).

A final issue to be considered is whether there might not be some other explanation for the absence of a gender congruency effect in plural NP production. The predictions we derived from the GSIH for plural NP production are based on the assumption that the gender feature is selected even in those cases where it might otherwise seem to be superfluous for determiner selection. It could be argued, however, that in the case of plural NPs in Dutch and German, where the same determiner forms and inflectional affixes are used for all genders, gender is not selected because its selection would have no consequence for picking a determiner form. Therefore, it is possible that the speech production system in these languages does not consider gender information when plural NPs are produced. If such were the case, potentially conflicting gender information would not be able to interfere because it is not selected in the plural condition. Such an account could potentially explain most of the data presented in this study (except for the target singular/distractor plural condition in Exp. 3). 
How might such a mechanism work? One would have to assume that feature selection is organized hierarchically such that the number feature dominates the gender feature, ensuring that number is selected before the gender feature is considered. One would further have to assume that the selection of the number feature 'plural' blocks the selection of the gender feature since the feature 'plural' is sufficient to correctly select the appropriate determiner (die in German or de in Dutch). Thus, it is possible to devise an organizational scheme for the selection of determiners in Dutch and German that prevents gender feature competition in the production of plural NPs while allowing it in the production of singular NPs. However, a system where gender is accessed only under some conditions (i.e., singular NPs) but not under others (i.e., plural NPs) is clearly ad hoc.

Furthermore, there is empirical evidence that gender is accessed even in plural NPs (Janssen \& Caramazza, in press; Schriefers et al., 2002). Schriefers et al. (2002) had German speakers name pictures with Det NPs and compared naming latencies for singular vs. plural NPs (e.g., der Helm 'the helmet' vs. die Helme, die Kerze 'the candle' vs. die Kerzen, das Pferd 'the horse' vs. die Pferde). The materials used in that study were the same as those used in Experiment 1a of the current study. While there was a cost for both masculine and neutral plural NPs relative to their singular NPs, feminine plural NPs were just as fast as feminine singular NPs. The authors interpret their data as follows: When masculine or neuter plural NPs are produced, there is a conflict between the determiner corresponding to the gender of the singular noun (e.g., der or das) and the determiner for plural NPs (e.g., die). This conflict does not occur in the case of feminine NPs since the singular and plural determiners are identical in that case. In a control experiment the same pictures were named using bare nouns and no differential effect of gender on singular and plural utterances occurred. If gender were not accessed in plural NPs in German, one would not expect a differential effect between feminine and masculine/neuter plural NPs relative to their singular NPs. The pattern of results reported by Schriefers et al. (2002, see also Footnote 6) indicates that during the production of plural Det NPs, singular and plural determiners compete for selection. Thus, their data support the claim that gender is accessed during the production of German plural NPs (for similar results in Dutch see Janssen \& Caramazza, in press, and Footnote 8).

Moreover, although we have noted that there are no instances in German (or Dutch) where gender information is needed directly for the purpose of selecting plural determiners or inflectional morphemes in simple Det $+\mathrm{N}$ or Adj $+\mathrm{N}$ phrases, cases exist in which gender is selected in plural NP production, e.g., complex NPs, anaphoric pronoun agreement, and elliptical constructions. For example, there are various situations where gender in- formation is needed for agreement in complex constructions. Consider the following examples:

(1) "eine ${ }_{(\mathrm{fem}, \mathrm{sg})}$ der $\operatorname{Katzen}_{(\mathrm{fem}, \mathrm{pl})}$ miaute" vs. $\operatorname{einer}_{(\mathrm{mas}, \mathrm{sg})}$ der Hunde (mas,pl) $_{\text {pll }}$ bellte"

['one of the cats miaowed' vs. 'one of the dogs barked']

The standard analysis of partitives (like "one of the cats") and related structures is as in (2)

(2)

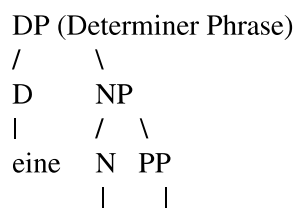

$e$ der Katzen

where " $e$ " is an empty noun (Chierchia, 1997; Selkirk, 1977). The arguments in favor of an analysis of partitives along the lines in (2) are straightforward: Normally, determiners do not select prepositional phrases (PPs). By positing a null noun the structure of the phrase is regularized; that is, partitives are reduced to independently established phrase structural configurations. On this analysis, the empty noun clearly does not have inherent features and therefore the gender information needed for selecting the correct form of the determiner eine/einer, einen/ein must be inherited from Katzen ('cats'). But for Katzen to play this role we must assume that its gender feature is selected in the course of NP production. Similar arguments are put forward by $\mathrm{Bi}-$ erwisch (2000). He argued that gender is lexically specified because it is a formal feature, which takes part in grammatical relations. Therefore, gender is retrieved even when a noun is in the plural.

Even though gender is not strictly necessary for determiner/inflection selection for plural NPs it is necessary for identity indexing. However, on the hierarchical selection scenario sketched above, the selection of the number feature 'plural' in an NP would block the selection of the gender feature of the noun, thereby blocking access to information that is necessary for selecting the form of the indefinite pronoun in constructions such as (1). If information about the gender of the referent were not available, speakers would not be able to select the correct gender-marked form of the pronoun. Therefore, we must assume that gender selection occurs in plural NP production. The hierarchical selection mechanism, which would block access to gender in plural constructions, cannot account for these results.

In conclusion, this study has produced evidence in support of the hypothesis that grammatical feature selection is an automatic, non-competitive process (Caramazza et al., 2001; Schiller and Caramazza, submitted). Word-specific grammatical features automatically become available as part of the selection of a lexical node. These grammatical features activate their 
associated form representations when the information cascades down to the level of phonological encoding. However, in German and Dutch the opportunity for competition in determiner form selection is only found with singular NPs. Plural NPs take the same determiner for all genders. Consistent with the DSIH, interference effects from gender-incongruent distractors were observed in the singular but not in the plural-both in German and in Dutch. This result suggests that the gender congruency effect first observed by Schriefers (1993) is a misnomer. A more appropriate name for the phenomenon is determiner congruency effect. The determiner congruency effect observed in German and Dutch reflects competition at the level of determiner form selection. Effects of determiner congruency between a target picture name and a distractor word are only found in languages where the selection of the determiner depends on the gender (and number) of the noun alone and thus can occur very early in the NP production process.

\section{Acknowledgments}

The research reported here was supported in part by NIH grants DC04542 to AC. Niels O. Schiller is supported by the Royal Dutch Academy of Arts and Sciences. The authors thank Michael Mengel, Arthur Jacobs, and Ralf Graf (all Catholic University of Eichstätt, Germany) for support in conducting Experiments 1a, 1b, and 1c, Suzan Kroezen (Max Planck
Institute for Psycholinguistics, Nijmegen, The Netherlands) for running subjects of Experiments 2b, 4a, and 4b, Bernadette Schmitt, Leo Blomert, and Holger Mitterer (all University of Maastricht, The Netherlands) as well as Stephen Rust (University of Braunschweig, Germany) for technical support in conducting Experiment 2a, and Frouke Hermens for running the subjects of Experiment 3. For discussion and helpful comments the authors thank Jens Bölte, Luigi Burzio, Gennaro Chierchia, Albert Costa, Ria De Bleser, Gisbert Fanselow, Gerard Kempen, Elisabeth Leiss, Alec Marantz, Dieter Wunderlich, Pienie Zwitserlood, and the members of the Utterance Encoding group at the Max Planck Institute for Psycholinguistics, Nijmegen, The Netherlands. Furthermore, we would especially like to thank Martin Pickering and an anonymous reviewer for their insightful reviews on the manuscript.

The paper benefited from discussions at the 40th Annual Meeting of the Psychonomic Society (L.A., Nov. 1999), Max Planck Institute for Psycholinguistics (Nijmegen, Dec. 1999), III Congreso de la Sociedad Española de Psicología Experimental (Barcelona, March 2000), 42. Tagung experimentell arbeitender Psychologen (Braunschweig, April 2000), 27th International Congress of Psychology (Stockholm, July 2000), AMLaP-2000 (Leiden, Sept. 2000), Second International Conference on the Mental Lexicon (Montreal, Oct. 2000), Brain and Behavioral Science Center (Birmingham, Nov. 2000), DFG workshop on gender processing (Leipzig, Dec. 2000), and the XII Conference of the European Society for Cognitive Psychology (Edinburgh, Sept. 2001).

\section{Appendix A}

Stimulus materials in Experiments 1a, 1b, and 1c

\begin{tabular}{|c|c|c|c|c|c|}
\hline \multirow[t]{2}{*}{ Target picture name } & \multirow[t]{2}{*}{ Gender } & \multicolumn{4}{|c|}{ Distractor word condition } \\
\hline & & Congruent & Gender & Incongruent & Gender \\
\hline Tür (‘door’) & Feminine & Kanne ('can') & Feminine & Kuchen ('cake') & Masculine \\
\hline Sonne ('sun') & Feminine & Pauke ('kettledrum') & Feminine & Pokal ('cup') & Masculine \\
\hline Schlange ('snake') & Feminine & Maske ('mask') & Feminine & Mond ('moon') & Masculine \\
\hline Eule ('owl') & Feminine & Geige ('violin') & Feminine & Galgen ('gallows') & Masculine \\
\hline Gans ('goose') & Feminine & Eiche ('oak') & Feminine & Eimer ('bucket') & Masculine \\
\hline Kerze ('candle') & Feminine & Laus ('louse') & Feminine & Löwe ('lion') & Masculine \\
\hline Leiter ('ladder') & Feminine & Kasse ('cash register') & Feminine & Kegel ('cone') & Masculine \\
\hline Bombe ('bomb’) & Feminine & Karte ('card') & Feminine & Knochen ('bone') & Masculine \\
\hline Hose ('pants') & Feminine & Kanzel ('pulpit') & Feminine & Karpfen ('carp') & Masculine \\
\hline Birne ('pear') & Feminine & Taube ('pigeon') & Feminine & Topf ('pot') & Masculine \\
\hline Boje ('buoy’) & Feminine & Harfe ('harp') & Feminine & Haar ('hair') & Neuter \\
\hline Palme ('palm tree') & Feminine & Ratte ('rat') & Feminine & Ruder ('oar') & Neuter \\
\hline Pfeife ('pipe') & Feminine & Nelke ('carnation') & Feminine & Netz ('net') & Neuter \\
\hline Nase ('nose') & Feminine & Butter ('butter') & Feminine & Beil ('axe') & Neuter \\
\hline Gabel ('fork') & Feminine & Perle ('pearl') & Feminine & Podest ('pedestal') & Neuter \\
\hline Brille ('glasses') & Feminine & Höhle ('cave') & Feminine & Hotel ('hotel') & Neuter \\
\hline Sichel ('sickle’) & Feminine & Pumpe ('pump') & Feminine & Pulver (powder) & Neuter \\
\hline Flasche ('bottle') & Feminine & Hexe ('witch') & Feminine & Heu ('hay') & Neuter \\
\hline Tulpe ('tulip') & Feminine & Bürste ('brush’) & Feminine & Bad ('bath') & Neuter \\
\hline
\end{tabular}


Appendix A (continued)

\begin{tabular}{|c|c|c|c|c|c|}
\hline \multirow[t]{2}{*}{ Target picture name } & \multirow[t]{2}{*}{ Gender } & \multicolumn{4}{|c|}{ Distractor word condition } \\
\hline & & Congruent & Gender & Incongruent & Gender \\
\hline Vase ('vase') & Feminine & Erbse ('pea') & Feminine & Ei ('egg') & Neuter \\
\hline Schlitten ('sled') & Masculine & Ball ('ball') & Masculine & Backe ('cheak') & Feminine \\
\hline Knopf ('button') & Masculine & Elch ('moose') & Masculine & Elster ('magpie') & Feminine \\
\hline Teller ('plate') & Masculine & Föhn ('hair dryer') & Masculine & Fackel ('torch') & Feminine \\
\hline Fuß ('foot') & Masculine & Gürtel ('belt') & Masculine & Glocke ('bell') & Feminine \\
\hline Tisch ('table') & Masculine & Garten ('garden') & Masculine & Gondel ('gondola') & Feminine \\
\hline Affe ('monkey') & Masculine & Filter ('filter') & Masculine & Feder ('feather') & Feminine \\
\hline Frosch ('frog') & Masculine & Arm ('arm’) & Masculine & Ader ('blood vessel') & Feminine \\
\hline Hund ('dog') & Masculine & Keller ('cellar') & Masculine & Kachel ('tile') & Feminine \\
\hline Helm ('helmet') & Masculine & Deckel ('tap') & Masculine & Düne ('dune') & Feminine \\
\hline Hammer ('hammer') & Masculine & Esel ('donkey’) & Masculine & Ente ('duck') & Feminine \\
\hline Schuh ('shoe') & Masculine & Hahn ('rooster') & Masculine & Holz ('wood') & Neuter \\
\hline Koffer ('suitcase') & Masculine & Ochse ('ox') & Masculine & Ohr ('ear') & Neuter \\
\hline Löffel ('spoon’) & Masculine & Kamin ('fire place') & Masculine & Kanu ('canoe') & Neuter \\
\hline Magnet ('magnet') & Masculine & Hals ('neck') & Masculine & Herz ('heart') & Neuter \\
\hline Kamm ('comb') & Masculine & Palast ('palace') & Masculine & Paket ('packet') & Neuter \\
\hline Korb ('basket') & Masculine & Pudel ('poodle') & Masculine & Pendel ('pendulum') & Neuter \\
\hline Ofen ('stove') & Masculine & Käfig ('cage') & Masculine & Kabel ('cable') & Neuter \\
\hline Schrank ('closet') & Masculine & Hamster ('hamster') & Masculine & Hemd ('shirt') & Neuter \\
\hline Stuhl ('chair') & Masculine & Keks ('cookie') & Masculine & Kleid ('dress') & Neuter \\
\hline Rock ('skirt') & Masculine & Herd ('oven') & Masculine & Huhn ('chicken') & Neuter \\
\hline Brot ('bread') & Neuter & Kalb ('calf') & Neuter & König ('king') & Masculine \\
\hline Bein ('leg') & Neuter & Papier ('paper') & Neuter & Panzer ('tank') & Masculine \\
\hline Zebra ('zebra') & Neuter & Parfum ('perfume') & Neuter & Pinsel ('brush') & Masculine \\
\hline Schaf ('sheep') & Neuter & Wasser ('water') & Neuter & Wald ('forest') & Masculine \\
\hline Buch ('book') & Neuter & Pflaster ('bandage') & Neuter & Pfeil ('arrow') & Masculine \\
\hline Messer ('knife') & Neuter & Reh ('deer') & Neuter & Ring ('ring') & Masculine \\
\hline Bett ('bed') & Neuter & Knie ('knee') & Neuter & Knoten ('knot') & Masculine \\
\hline Pferd ('horse') & Neuter & Blut ('blood') & Neuter & Brief ('letter') & Masculine \\
\hline Kamel ('camel') & Neuter & Meer ('sea') & Neuter & Motor ('motor') & Masculine \\
\hline Schiff ('ship’) & Neuter & Rind ('cow') & Neuter & Reifen ('wheel') & Masculine \\
\hline Zelt ('tent') & Neuter & Feuer ('fire') & Neuter & Fliege ('fly') & Feminine \\
\hline Lasso ('lasso') & Neuter & Feld ('field') & Neuter & Frucht ('fruit') & Feminine \\
\hline Faß ('barrel') & Neuter & Moped ('moped') & Neuter & Mauer ('wall') & Feminine \\
\hline Klavier ('piano') & Neuter & Grab ('grave') & Neuter & Gurke ('cucumber') & Feminine \\
\hline Glas ('glas') & Neuter & Floß ('raft') & Neuter & Flöte ('fluit') & Feminine \\
\hline Regal ('shelf') & Neuter & Fenster ('window') & Neuter & Fahne ('flag') & Feminine \\
\hline Kissen ('pillow') & Neuter & Metall ('metal') & Neuter & Maus ('mouse') & Feminine \\
\hline Haus ('house') & Neuter & Loch ('hole') & Neuter & Lippe ('lip’) & Feminine \\
\hline Auto ('car') & Neuter & Licht ('light') & Neuter & Liege ('couch') & Feminine \\
\hline Blatt ('leaf') & Neuter & Lamm ('lamb') & Neuter & Lampe ('lamp') & Feminine \\
\hline
\end{tabular}

\section{Appendix B}

Stimulus materials in Experiments 2a, 2b, and 3

\begin{tabular}{|c|c|c|c|c|c|}
\hline \multirow[t]{2}{*}{ Target picture name } & \multirow[t]{2}{*}{ Gender } & \multicolumn{4}{|c|}{ Distractor word condition } \\
\hline & & Congruent & Gender & Incongruent & Gender \\
\hline poes ('cat') & Common & kerk ('church') & Common & blad ('leaf') & Neuter \\
\hline fabriek ('factory') & Common & muis ('mouse') & Common & pak ('suit') & Neuter \\
\hline stoel ('chair') & Common & jas ('jacket') & Common & kasteel ('castle') & Neuter \\
\hline vork ('fork') & Common & zoon ('son') & Common & touw ('rope') & Neuter \\
\hline mond ('mouth') & Common & zeep ('soap') & Common & nest ('nest') & Neuter \\
\hline tafel ('table') & Common & kers ('cherry') & Common & glas ('glas') & Neuter \\
\hline gitaar ('guitar') & Common & ladder ('ladder') & Common & strand ('beach') & Neuter \\
\hline
\end{tabular}




\begin{tabular}{|c|c|c|c|c|c|}
\hline \multirow[t]{2}{*}{ Target picture name } & \multirow[t]{2}{*}{ Gender } & \multicolumn{4}{|c|}{ Distractor word condition } \\
\hline & & Congruent & Gender & Incongruent & Gender \\
\hline zaag ('saw’) & Common & klap ('bang') & Common & papier ('paper') & Neuter \\
\hline trein ('train') & Common & schoen ('shoe') & Common & brood ('bread') & Neuter \\
\hline taart ('cake') & Common & auto ('car') & Common & bureau ('desk') & Neuter \\
\hline fles ('bottle') & Common & staart ('tail') & Common & schaak ('chess') & Neuter \\
\hline konijn ('rabbit') & Neuter & pak ('suit') & Neuter & kerk ('church') & Common \\
\hline huis ('house') & Neuter & blad ('leaf') & Neuter & jas ('jacket') & Common \\
\hline hemd ('shirt') & Neuter & kasteel ('castle') & Neuter & muis ('mouse') & Common \\
\hline been ('leg’) & Neuter & strand ('beach') & Neuter & auto ('car') & Common \\
\hline geweer ('rifle') & Neuter & bureau ('desk') & Neuter & staart ('tail') & Common \\
\hline schaap ('sheep') & Neuter & brood ('bread') & Neuter & kers ('cherry') & Common \\
\hline wiel ('wheel') & Neuter & nest ('nest') & Neuter & zeep ('soap') & Common \\
\hline boek ('book') & Neuter & glas ('glas') & Neuter & klap ('bang') & Common \\
\hline paard ('horse') & Neuter & touw ('rope') & Neuter & zoon ('son') & Common \\
\hline bed ('bed') & Neuter & papier ('paper') & Neuter & ladder ('ladder') & Common \\
\hline raam ('window') & Neuter & schaak ('chess') & Neuter & schoen ('shoe') & Common \\
\hline
\end{tabular}

\section{Appendix C}

Stimulus materials in Experiments $4 \mathrm{a}$ and $4 \mathrm{~b}$

\begin{tabular}{|c|c|c|c|c|c|}
\hline \multirow[t]{2}{*}{ Target picture name } & \multirow[t]{2}{*}{ Gender } & \multicolumn{4}{|c|}{ Distractor word condition } \\
\hline & & Congruent & Gender & Incongruent & Gender \\
\hline poes ('cat') & Common & kerk ('church') & Common & blad ('leaf') & Neuter \\
\hline wortel ('carrot') & Common & muis ('mouse') & Common & stuur ('wheel') & Neuter \\
\hline stoel ('chair') & Common & jas ('jacket') & Common & plein ('square') & Neuter \\
\hline vork ('fork') & Common & zoon ('son') & Common & touw ('rope') & Neuter \\
\hline mond ('mouth') & Common & zeep ('soap') & Common & nest ('nest') & Neuter \\
\hline tafel ('table') & Common & kers ('cherry') & Common & glas ('glas') & Neuter \\
\hline gitaar ('guitar') & Common & ladder ('ladder') & Common & strand ('beach') & Neuter \\
\hline zaag ('saw') & Common & klap ('bang') & Common & papier ('paper') & Neuter \\
\hline trein ('train') & Common & schoen ('shoe') & Common & hoofd ('head') & Neuter \\
\hline taart ('cake') & Common & auto ('car') & Common & bureau ('desk') & Neuter \\
\hline fles ('bottle') & Common & staart ('tail') & Common & wiel ('wheel') & Neuter \\
\hline konijn ('rabbit') & Neuter & stuur ('wheel') & Neuter & kerk ('church') & Common \\
\hline kasteel ('castle') & Neuter & blad ('leaf') & Neuter & jas ('jacket') & Common \\
\hline hemd ('shirt') & Neuter & wiel ('wheel') & Neuter & muis ('mouse') & Common \\
\hline been ('leg') & Neuter & strand ('beach') & Neuter & auto ('car') & Common \\
\hline geweer ('rifle') & Neuter & bureau ('desk') & Neuter & staart ('tail') & Common \\
\hline schaap ('sheep') & Neuter & nest ('nest') & Neuter & kers ('cherry') & Common \\
\hline schip ('ship') & Neuter & glas ('glass') & Neuter & zeep ('soap') & Common \\
\hline brood ('bread') & Neuter & plein ('square') & Neuter & klap ('bang') & Common \\
\hline paard ('horse') & Neuter & touw ('rope') & Neuter & zoon ('son') & Common \\
\hline bed ('bed') & Neuter & papier ('paper') & Neuter & ladder ('ladder') & Common \\
\hline raam ('window') & Neuter & hoofd ('head') & Neuter & schoen ('shoe') & Common \\
\hline poes ('cat') & Common & hamster ('hamster') & Common & poets ('trick') & Common \\
\hline wortel ('carrot') & Common & asperge ('asparagus') & Common & worm ('worm') & Common \\
\hline stoel ('chair') & Common & bank ('couch') & Common & stoep ('pavement') & Common \\
\hline vork ('fork') & Common & lepel ('spoon') & Common & vonk ('spark') & Common \\
\hline mond ('mouth') & Common & neus ('nose') & Common & monnik ('monk') & Common \\
\hline tafel ('table') & Common & kast ('cupboard') & Common & tabak ('tobacco') & Common \\
\hline gitaar ('guitar') & Common & cello ('cello') & Common & giraf ('giraffe') & Common \\
\hline zaag ('saw') & Common & hamer ('hammer') & Common & zaak ('thing') & Common \\
\hline trein ('train') & Common & bus ('bus') & Common & trede ('step') & Common \\
\hline taart ('cake') & Common & koek ('cake') & Common & taal ('language') & Common \\
\hline fles ('bottle') & Common & kan ('jug') & Common & fluit ('flute') & Common \\
\hline konijn ('rabbit') & Neuter & lam ('lamb') & Neuter & koren ('corn') & Neuter \\
\hline
\end{tabular}


Appendix C (continued)

\begin{tabular}{|c|c|c|c|c|c|}
\hline \multirow[t]{2}{*}{ Target picture name } & \multirow[t]{2}{*}{ Gender } & \multicolumn{4}{|c|}{ Distractor word condition } \\
\hline & & Congruent & Gender & Incongruent & Gender \\
\hline kasteel ('castle') & Neuter & huis ('house') & Neuter & katoen ('cotton') & Neuter \\
\hline hemd ('shirt') & Neuter & pak ('suit') & Neuter & hek ('fence') & Neuter \\
\hline been ('leg') & Neuter & oor ('ear') & Neuter & beeld ('statue') & Neuter \\
\hline geweer ('rifle') & Neuter & kanon ('gun’) & Neuter & gewicht ('weight') & Neuter \\
\hline schaap ('sheep') & Neuter & hert ('deer') & Neuter & schaak ('chess') & Neuter \\
\hline schip ('ship') & Neuter & veer ('ferry') & Neuter & schild ('shield') & Neuter \\
\hline brood ('bread') & Neuter & ei ('egg') & Neuter & brein ('brain') & Neuter \\
\hline paard ('horse') & Neuter & varken ('pig') & Neuter & paleis ('palace') & Neuter \\
\hline bed ('bed') & Neuter & rek ('rack') & Neuter & beest ('animal') & Neuter \\
\hline raam ('window') & Neuter & luik ('hatch') & Neuter & rag ('cobweb') & Neuter \\
\hline Filler picture name & Gender & Distrator word & Gender & & \\
\hline bijl ('axe') & Common & haan ('rooster') & Common & & \\
\hline bril ('glasses') & Common & kwast ('brush') & Common & & \\
\hline eend ('duck') & Common & jurk ('dress') & Common & & \\
\hline fiets ('bike') & Common & tand ('tooth') & Common & & \\
\hline hoed ('hat') & Common & bal ('ball') & Common & & \\
\hline schaar ('scissors') & Common & tijger ('tiger') & Common & & \\
\hline vis ('vis') & Common & klomp ('clog') & Common & & \\
\hline hand ('hand') & Common & zon ('sun’) & Common & & \\
\hline klok ('clock') & Common & schaats ('skate') & Common & & \\
\hline bloem ('flower') & Common & maan ('moon') & Common & & \\
\hline tent ('tent') & Common & noot ('nut') & Common & & \\
\hline trompet ('trumpet') & Common & kaart ('card') & Common & & \\
\hline kaars ('candle') & Common & trui ('sweater') & Common & & \\
\hline aap ('monkey') & Common & emmer ('bucket') & Common & & \\
\hline peer ('pear') & Common & wolk ('cloud') & Common & & \\
\hline kleed ('carpet') & Neuter & circus ('circus') & Neuter & & \\
\hline masker ('mask') & Neuter & bord ('plate') & Neuter & & \\
\hline mes ('knife') & Neuter & dak ('roof') & Neuter & & \\
\hline net ('net') & Neuter & blik ('can') & Neuter & & \\
\hline oog ('eye') & Neuter & web ('web') & Neuter & & \\
\hline penseel ('brush') & Neuter & geld ('money') & Neuter & & \\
\hline spook ('ghost') & Neuter & lint ('ribbon') & Neuter & & \\
\hline zwaard ('sword') & Neuter & blok ('block') & Neuter & & \\
\hline harp ('harp') & Neuter & robot ('robot') & Neuter & & \\
\hline bot ('bone') & Neuter & laken ('sheet') & Neuter & & \\
\hline kruis ('cross') & Neuter & schort ('apron') & Neuter & & \\
\hline slot ('lock') & Neuter & kalf ('calf') & Neuter & & \\
\hline fornuis ('stove') & Neuter & vest ('vest') & Neuter & & \\
\hline potlood ('pencil') & Neuter & monster ('monster') & Neuter & & \\
\hline anker ('anchor') & Neuter & zadel ('saddle') & Neuter & & \\
\hline boek ('book') & Neuter & spel ('game') & Neuter & & \\
\hline hart ('heart') & Neuter & orgel ('organ') & Neuter & & \\
\hline
\end{tabular}

\section{References}

Alario, F.-X., \& Caramazza, A. (2002). The production of determiners: Evidence from French. Cognition, 82, 179-223.

Baayen, R. H., Piepenbrock, R., \& Gulikers, L. (1995). The CELEX lexical database (CD-ROM). Philadelphia, PA: Linguistic Data Consortium, University of Pensylvania.

Bierwisch, M. (2000). Genus, Sexus, und der Status morphologischer Merkmale [Gender, sex, and the state of morphological features]. Paper presented at the DFG workshop "Verarbeitung von syntaktischem Genus in der
Sprachproduktion" ['Processing of syntactic gender in speech production'], Leipzig, Germany.

Caramazza, A. (1997). How many levels of processing are there in lexical access? Cognitive Neuropsychology, 14, 177-208.

Caramazza, A., \& Miozzo, M. (1997). The relation between syntactic and phonological knowledge in lexical access: Evidence from the 'tip-of-the-tongue' phenomenon. Cognition, 64, 309-343.

Caramazza, A., Miozzo, M., Costa, A., Schiller, N. O., \& Alario, F.-X. (2001). A cross-linguistic investigation of determiner production. In E. Dupoux (Ed.), Language, 
Brain and Cognitive Development: Essays in Honor of Jacques Mehler (pp. 209-226). Cambridge, MA: MIT Press.

Chierchia, G. (1997). Partitives, reference to kinds and semantic variation. In Proceedings of SALT 7, Cornell Linguistic Circle, Cornell University, Ithaca.

Corbett, G. (1991). Gender. Cambridge, MA: Cambridge University Press.

Costa, A., Sebastián-Gallés, N., Miozzo, M., \& Caramazza, A. (1999). The gender congruity effect: Evidence from Spanish and Catalan. Language and Cognitive Processes, 14, 381391.

Costa, A., Kovacic, D., \& Caramazza, A. (submitted). The gender congruency effect and the selection of adjective inflections and pronouns in Croatian.

Deutsch, W., \& Wijnen, F. (1985). The article's noun and the noun's article: Explorations into the representation and access of linguistic gender in Dutch. Linguistics, 23, 793 810.

Glaser, W. R. (1992). Picture naming. Cognition, 42, 61-105.

Glaser, W. R., \& Düngelhoff, F.-J. (1984). The time course of picture-word interference. Journal of Experimental Psychology: Human Perception and Performance, 10, 640-654.

Glaser, W. R., \& Glaser, M. O. (1989). Context effects in Stroop-like word and picture processing. Journal of Experimental Psychology: General, 118, 13-42.

Gum, T., \& Bub, D. (1988). PsychLab manual. Montreal: McGill University.

Janssen, N., \& Caramazza, A. (in press). Determiner selection in diminutive and plural noun phrases in Dutch. Journal of Memory and Language.

Köpcke, K.-M., \& Zubin, D. (1984). Sechs Prinzipien für die Genuszuweisung im Deutschen: Ein Beitrag zur natürlichen Klassifikation ['Six principles for gender assignment in German: A contribution for natural classification']. Linguistische Berichte, 93, 26-50.

La Heij, W., Mak, P., Sander, J., \& Willeboordse, E. (1998). The gender-congruency effect in picture-word tasks. Psychological Research, 61, 209-219.

Lehmann, W. P. (1958). On earlier stages of the Indo-European nominal inflection. Language, 34, 179-202.

Leiss, E. (1999). Gender in Old High German. In B. Unterbeck \& M. Rissanen (Eds.), Gender in grammar and cognition (pp. 225-244). Berlin: Mouton de Guyter.

Levelt, W. J. M. (1989). Speaking. From intention to articulation. Cambridge, MA: MIT Press.

Levelt, W. J. M., Roelofs, A., \& Meyer, A. S. (1999). A theory of lexical access in speech production. Behavioral and Brain Sciences, 22, 1-75.

Lupker, S. J. (1979). The semantic nature of response competition in the picture-word interference task. Memory \& Cognition, 7, 485-495.

Lupker, S. J. (1982). The role of phonetic and orthographic similarity in picture-word interference. Canadian Journal of Psychology, 36, 349-367.

MacLeod, C. M. (1991). Half a century of research on the Stroop effect: An integrative review. Psychological Bulletin, 109, 163-203.
Meyer, A. S. (1996). Lexical access in phrase and sentence production: Results from picture-word interference experiments. Journal of Memory and Language, 35, 477-496.

Meyer, A. S., \& Schriefers, H. (1991). Phonological facilitation in picture-word interference experiments: Effects of stimulus onset asynchrony and types of interfering stimuli. Journal of Experimental Psychology: Learning, Memory, and Cognition, 17, 1146-1160.

Miozzo, M., \& Caramazza, A. (1999). The selection of determiners in noun phrase production. Journal of Experimental Psychology: Learning, Memory, and Cognition, 25, 907-922.

Miozzo, M., Costa, A., \& Caramazza, A. (2002). The timecourse of the gender congruence effect in Spanish and Italian. Journal of Experimental Psychology: Learning, Memory, and Cognition, 28, 388-391.

Posnansky, C. J., \& Rayner, K. (1977). Visual-feature and response components in a picture-word interference task with beginning and skilled readers. Journal of Experimental Child Psychology, 24, 440-460.

Rosinski, R. R., Golinkoff, R. M., \& Kukish, K. S. (1975). Automatic semantic processing in a picture-word interference task. Child Development, 46, 247-253.

Schiller, N. O., \& Caramazza, A. (2002). The selection of grammatical features in word production: The case of plural nouns in German. Brain and Language, 81, 342-357.

Schiller, N. O., \& Caramazza, A. (submitted). Grammatical gender selection in language production: The case of Dutch diminutives.

Schriefers, H. (1992). Lexical access in the production of noun phrases. Cognition, 45, 33-54.

Schriefers, H. (1993). Syntactic processes in the production of noun phrases. Journal of Experimental Psychology: Learning, Memory, and Cognition, 19, 841-850.

Schriefers, H., Jescheniak, J. D., \& Hantsch, A. (2002). Determiner selection in noun phrase production. Journal of Experimental Psychology: Learning, Memory, and Cognition, 28, 941-950.

Schriefers, H., Meyer, A. S., \& Levelt, W. J. M. (1990). Exploring the time course of lexical access in languageproduction: Picture-word interference studies. Journal of Memory and Language, 29, 86-102.

Schriefers, H., \& Teruel, E. (2000). Grammatical gender in noun phrase production: The gender interference effect in German. Journal of Experimental Psychology: Learning, Memory, and Cognition, 26, 1368-1377.

Selkirk, E. (1977). Some remarks on noun phrase structure. In P. W. Culicover, T. Wasow, \& A. Akmajian (Eds.), Formal syntax (pp. 285-316). New York: Academic Press.

Stroop, J. R. (1935). Studies of interference in serial verbal reactions. Journal of Experimental Psychology, 18, 643662.

Van Berkum, J. J. A. (1996). The psycholinguistics of grammatical gender. Studies in language comprehension and production. Unpublished Ph.D. Dissertation, Nijmegen University.

Van Berkum, J. J. A. (1997). Syntactic processes in speech production: The retrieval of grammatical gender. Cognition, $64,115-152$. 